First publ. in: Journal of the American Chemical Society, 131 (2009), 13, pp. 4892-4903

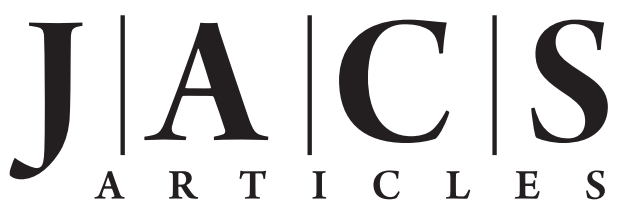

Published on Web 03/11/2009

\title{
Electron Transfer Across Multiple Hydrogen Bonds: The Case of Ureapyrimidinedione-Substituted Vinyl Ruthenium and Osmium Complexes
}

\author{
Markus Pichlmaier, ${ }^{\dagger}$ Rainer F. Winter, ${ }^{*, \dagger}$ Manfred Zabel, ${ }^{\dagger}$ and Stanislav Záliš ${ }^{*, \neq}$ \\ Institut für Anorganische Chemie der Universität Regensburg, D-93040 Regensburg, Germany, \\ and J. Heyrovsky Institute of Physical Chemistry, v.v.i, Academy of Sciences of the Czech \\ Republic, Czech Republic
}

Received December 16, 2008; E-mail: rainer.winter@chemie.uni-regensburg.de; stanislav.zalis@jh-inst.cas.cz

\begin{abstract}
Ruthenium and osmium complexes $\mathbf{2} \mathbf{a}, \mathbf{b}$ and $\mathbf{3 a} \mathbf{a} \mathbf{b}$ featuring the $\mathbf{N - 4 , 6 - d i o x o - 5 , 5 - d i b u t y l -}$ or the $N$-4,6-dioxo-5,5-di-(2-propenyl)-1,4,5,6-tetrahydropyrimidin-2-yl- $N$ (4-ethenylphenyl)-urea ligand dimerize by a self-complementary quadruply hydrogen-bonding donor/donor/acceptor/acceptor (DDAA) motif. We provide evidence that the dimeric structures are maintained in nonpolar solvents and in $0.1 \mathrm{M} \mathrm{NBu}_{4} \mathrm{PF}_{6} / \mathrm{CH}_{2} \mathrm{Cl}_{2}$ supporting electrolyte solution. All complexes are reversibly oxidized in two consecutive two-electron oxidations $\left(\Delta E_{1 / 2} \approx 500 \mathrm{mV}\right)$ without any discernible potential splitting for the oxidation of the individual hydrogen-bridged redox active moieties. IR and UV/vis/NIR spectroelectrochemistry show a one-step conversion of the neutral to the dication without any discernible features of an intermediate monooxidized radical cation. Oxidation-induced IR changes of the $\mathrm{NH}$ and $\mathrm{CO}$ groups that are involved in hydrogen bonding are restricted to the styryl-bonded urea $\mathrm{NH}$ function. IR band assignments are aided by quantum chemical calculations. Our experimental findings clearly show that, at least in the present systems, the ureapyrimidinedione (Upy) DDAA hydrogen-bonding motif does not support electron transfer. The apparent reason is that neither of the hydrogen-bonding functionalities contributes to the occupied frontier levels. This results in nearly degenerate pairs of MOs representing the in-phase and out-of-phase combinations of the individual monomeric building blocks.
\end{abstract}

\section{Introduction}

Electron transfer is one of the most fundamental processes in chemistry and biology. The spatial organization of the electron donor and the electron acceptor in proteins, peptides, and enzymes as well as the rate of electron transfer between them critically depends on the structure-directing and charge-transmitting properties of hydrogen bridges ${ }^{1-5}$ as is exemplified by photosystem $\mathrm{II}^{6,7}$ and cytochrome $c .{ }^{8,9}$ The search for strong, multiple hydrogen bridges as a tool for the directed organization of matter in synthetical supramolecular systems has led to the

\footnotetext{
Institut für Anorganische Chemie der Universität Regensburg.

$\div$ J. Heyrovský Institute of Physical Chemistry, v.v.i, Academy of Sciences of the Czech Republic.

(1) Gray, H. B.; Winkler, J. R. In Electron Transfer in Chemistry and Biology; Balzani, V., Ed.; Wiley-VCH: Weinheim, 2001; Vol. 1, p 3.

(2) Antonello, S.; Formaggio, F.; Moretto, A.; Toniolo, C.; Maran, F. J. Am. Chem. Soc. 2003, 125, 2874-2875.

(3) Serron, S. A.; Aldridge, W. S., III; Fleming, C. N.; Danell, R. M.; Baik, M.-H.; Sykora, M.; Dattelbaum, D. M.; Meyer, T. J. J. Am. Chem. Soc. 2004, 126, 14506-14514.

(4) Kümmerle, R.; Kyritsis, P.; Gaillard, J.; Moulis, J.-M. J. Inorg. Biochem. 2000, 79, 83-91.

(5) Stubbe, J.; Nocera, D.; Yee, C. S.; Chang, M. C. Y. Chem. Rev. 2003, 103, 2167-2202.

(6) Zhang, C. Biochim. Biopphys. Acta, Bioenerg. 2007, 1767, 493-499.

(7) Semin, B. K.; Lovyagina, E. R.; Timofeev, K. N.; Ivanov, I. I.; Rubin, A. B.; Seibert, M. Biochemistry 2005, 44, 9746-9757.

(8) Liu, H.; Yamamoto, H; J, Wei; Waldeck, D. H. Langmuir 2003, 19, 2378-2387.

(9) Langen, R.; Colón, J. L.; Casimiro, D. R.; Karpishin, T. B.; Winkler, J. R.; Gray, H. B. J. Biol. Inorg. Chem. 1996, 1, 221-225.
}

elaboration of several new and interesting motifs. Among these, the self-complementary DDAA arrangement of two hydrogen bond donor (D) and acceptor (A) sites as it is present in ureapyrimidones or urea- $s$-triazines has been a particular success story. ${ }^{10-13}$ Self-complementary quadruple hydrogen bridges lead to high association constants of $\sim 10^{5}-10^{7}$ in apolar solvents. This has allowed for the formation of hydrogen-bonded linear or cross-linked macrocycles, ${ }^{14}$ and of oligomers or polymers that reversibly assemble or disintegrate upon changing the polarity and hydrogen-bonding capability of the surrounding medium. ${ }^{13-17}$ One disadvantage of the latter systems is the frequently observed formation of complex equilibria involving different interconverting tautomers with hard-to-predict tautomer

(10) Beijer, F. H.; Sijbesma, R. P.; Kooijman, H.; Spek, A. L.; Meijer, E. W. J. Am. Chem. Soc. 1998, 120, 6761-6769.

(11) Sijbesma, R. P.; Meijer, E. W. Chem. Commun. 2003, 5-16.

(12) Corbin, P. S.; Zimmerman, S. C. J. Am. Chem. Soc. 1998, 120, 97109711.

(13) Schmuck, C.; Wienand, W. Angew. Chem., Int. Ed. 2001, 40, 43634369.

(14) Hirschberg, J. H. H. K.; Koevoets, R. A.; Sijbesma, R. P.; Meijer, E. W Chem. Eur. J. 2003, 9, 4222-4231.

(15) Binder, W. H.; Zirbs, R. Supramolecular Polymers and Networks with Hydrogen Bonds in the Main- and Side-Chain. In Hydrogen Bonded Polymers; Binder, W., Ed.; SpringerLink: Heidelberg, 2007; Vol. 207, pp 1-78.

(16) Vázquez-Campos, S.; Crego-Calama, M.; Reinhoudt, D. N. Supramol. Chem. 2007, 19, 95-106.

(17) Sherrington, D. C.; Taskinen, K. A. Chem. Soc. Rev. 2001, 30, 8393. 
Chart 1. Degenerate Tautomerism and Dimerization of N-5,5-Dialkyl-4,6-dioxo-1,4,5,6-tetrahydropyrimidin-2-yl-urea derivatives $^{a}$

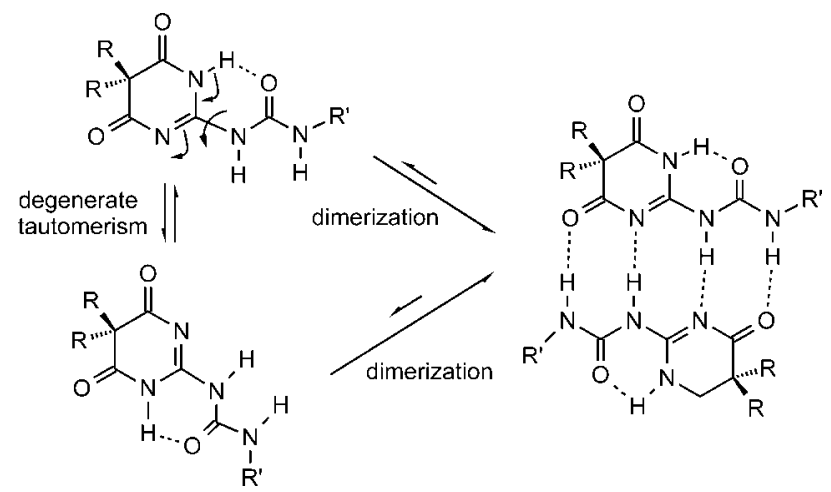

${ }^{a}$ The singly oxidized form of a ferrocenyl substituted dimer $\left(\mathrm{R}^{\prime}=\right.$ ferrocenyl) shows borderline class II/III mixed-valent behaviour. ${ }^{23}$

distributions. $^{12,18}$ Symmetrically substituted 5,5-dialkyl-4,6dioxo-1,4,5,6-tetrahydro-pyrimidin-2-yl-urea derivatives have finally resolved the problem of nondegenerate tautomerism (Chart 1). ${ }^{19}$

Ureido-s-triazine-bridged assemblies of various oligo(phenylenevinylene) donors and the perylene bisimide acceptor ${ }^{20}$ and noncovalently bonded dimers of amidinium-substituted metalloporphyrins $^{21}$ or tetrathiofulvalenes ${ }^{22}$ and a fullerenesubstituted benzoate provide intriguing examples of efficient photochemically triggered electron transfer from the excited donor to the acceptor across strong hydrogen bridges. Directed energy transfer in these systems profits from the thermodynamic driving force imminent in the relaxation of an electron from a higher-energy orbital at the excited donor to the lower-lying LUMO localized at the acceptor site. Recent work on the $N$-4,6dioxo-1,4,5,6-tetrahydropyrimidin-2-yl- $N^{\prime}$-ferrocenylurea dimer (Chart $1, \mathrm{R}^{\prime}=$ ferrocenyl) indicated efficient electron transfer across strong hydrogen bonds in a degenerate mixed-valent state, i.e. as a self-exchange without a thermodynamic driving force. ${ }^{23}$ In $\mathrm{CH}_{2} \mathrm{Cl}_{2}$ the mixed-valent $\mathrm{Fc} / \mathrm{Fc}^{+}$congener of the latter compound reportedly displays an intense narrow intervalence charge-transfer band in the near-infrared (NIR) as it is characteristic of a borderline Class II/III system according to the Robin and Day classification scheme. ${ }^{24}$

Styryl ruthenium complexes $(\mathrm{PhCH}=\mathrm{CH}) \mathrm{Ru}(\mathrm{CO}) \mathrm{Cl}\left(\mathrm{PR}_{3}\right)_{2}(\mathrm{R}$ $\left.=\mathrm{Ph},{ }^{i} \mathrm{Pr}\right)$ undergo one-electron oxidation at a potential of 0.33 $\mathrm{V}(\mathrm{R}=\mathrm{Ph})$ or $0.28 \mathrm{~V}\left(\mathrm{R}={ }^{i} \mathrm{Pr}\right.$, measured against the ferrocene/ ferrocenium couple) that is dominated by the styryl ligand. ${ }^{25}$

(18) Söntjens, S. H. M.; Sijbesma, R. P.; van der Genderen, M. H. P.; Meijer, E. W. J. Am. Chem. Soc. 2000, 122, 7487-7493.

(19) Baruah, P. K.; Gonnade, R.; Phalgune, U. D.; Sanjayan, G. D. J. Org. Chem. 2005, 70, 6461-6467.

(20) Zhang, J.; Hoeben, F. J. M.; Pouderoijen, M. J.; Schenning, A. P. H. J.; Meijer, E. W.; De Schryver, F. C.; De Feyter, S. Chem. Eur. J. 2006, 12, 9046-9055.

(21) Sánchez, L; Sierra, M; Martín, N.; Myles, A. J.; Dale, T. J.; Rebek, J., Jr.; Seitz, W.; Guldi, D. M Angew. Chem. 2006, 118, 4753-4757.

(22) Segura, M. L; Sánchez de Mendoza, J; Martín, N.; Guldi, D. M. J. Am. Chem. Soc. 2003, 125, 15093-15100.

(23) Sun, H.; Steeb, J.; Kaifer, A. E. J. Am. Chem. Soc. 2006, 128, 28202821.

(24) Robin, M. B.; Day, P. Adv. Inorg. Chem. Radiochem. 1967, 10, 247422.

(25) Maurer, J; Linseis, M; Sarkar, B.; Schwerderski, B.; Niemeyer, M.; Kaim, W.; Záliš, S; Anson, C.; Zabel, M.; Winter, R. F. J. Am. Chem. Soc. 2008, 130, 259-268.
The unpaired spin of the associated radical cation is delocalized over the styryl entity with minor contributions of $\sim 25-30 \%$ from the $\mathrm{Ru}\left(\mathrm{PR}_{3}\right)_{2}$ moieties. The total spin density on the phenyl substituent of oxidized ruthenium styryl complexes $(\sim 30 \%)$ clearly surpasses that on a cyclopentadienyl ligand in ferrocinium ions. We therefore mused that electronic interactions in partially oxidized mixed-valent forms of hydrogen bonded, dimeric styryl ruthenium complexes should even be stronger than those in the analogous ferrocene system. $\mathrm{Ru}\left(\mathrm{PR}_{3}\right)_{2}(\mathrm{CO}) \mathrm{Cl}$ substituted vinyl complexes have the added benefit of providing charge-sensitive IR labels by virtue of the ruthenium bonded carbonyl and vinyl ligands. The shift and pattern of the $\mathrm{CO}$ and vinyl vibrations upon oxidation may thus be used for mapping the efficacy and time scale of intramolecular electron transfer. These assets have successfully been employed to establish charge and spin delocalization in divinylphenylene and butadienediyl bridged diruthenium complexes. ${ }^{26-28}$ We therefore prepared and investigated $N$-4,6-dioxo-5,5-dibutyl- and $N$-4,6-dioxo-5,5-di-(2-propenyl)-1,4,5,6-tetrahydropyrimidin-2yl- $N$ '-(4-ethynylphenyl)urea and the corresponding $\mathrm{P}^{i} \mathrm{Pr}_{3}$ ligated ruthenium and osmium styryl derivatives. The results on these hydrogen-bonded, dimeric complexes are compared to those on a monomeric $N$-phenyl- $N^{\prime}$-(4-ethenylphenyl)urea ruthenium derivative lacking the pyrimidinedione hydrogen-bond-accepting moiety.

\section{Results}

Tetrahydropyrimidine-Substituted (4-Ethynylphenyl)urea Derivatives and 4-Styrylurea Complexes. The styryl ruthenium and osmium complexes $\mathbf{2 a}, \mathbf{b}$ and $\mathbf{3 a}, \mathbf{b}$ with an appended quadruply hydrogen-bonding moiety were synthesized by reacting the corresponding 4-ethynylphenyl-substituted ureapyrimidinedione (Upy) with the hydride complexes $\mathrm{HM}(\mathrm{CO}) \mathrm{Cl}\left(\mathrm{P}^{i} \mathrm{Pr}_{3}\right)_{2}$ $(\mathrm{M}=\mathrm{Ru}, \mathrm{Os})$ in $\mathrm{CH}_{2} \mathrm{Cl}_{2}$ according to Scheme 1. The known $N$-4,6-dioxo-5,5-dibutyl- and $N$-4,6-dioxo-5,5-di-(2-propenyl)1,4,5,6-tetrahydropyrimidin-2-yl- $N^{\prime}$-(4-ethynylphenyl)urea derivatives $\mathbf{1 a}, \mathbf{b}^{19}$ were prepared in three steps from the respective disubstituted malonate, guanidinium hydrochloride, and 4-ethynylphenylisocyanate, which in turn was available from commercial 4-ethynylaniline and triphosgene. The identity of the compounds as the target styryl complexes was readily established by virtue of the ${ }^{1} \mathrm{H}$ NMR signals of an $\mathrm{ABX}_{2}$-spin system of the vinyl protons at 8.6-8.2 $\mathrm{ppm}(\mathrm{MCH})$ and at 6.0-5.5 ppm $(\mathrm{MCH}=\mathrm{CH})$ with clearly resolved ${ }^{4} \mathrm{~J}$ coupling to two equivalent phosphorus nuclei for the latter one, the typical vinyl resonances in ${ }^{13} \mathrm{C} \mathrm{NMR}$ at $\sim 150 \mathrm{ppm}\left(\mathrm{M}-C_{\alpha}\right)$ or $135 \mathrm{ppm}$ $\left(\mathrm{M}-\mathrm{C}_{\alpha}=C_{\beta}\right)$, the singlet resonance in ${ }^{31} \mathrm{P} \mathrm{NMR}$ of the equivalent phosphorus nuclei and the single $\mathrm{CO}$ band at $1910(\mathrm{M}=\mathrm{Ru})$ or $1895(\mathrm{M}=\mathrm{Os}) \mathrm{cm}^{-1}$ in the IR. Owing to the solubilizing substituents at the 5-positions of the Upy skeleton and the $\mathrm{P}^{i} \mathrm{Pr}_{3}$ ligands, all complexes readily dissolve in low-polarity solvents such as chloroform, dichloromethane, THF, or mixtures of these solvents with methanol, while they are only sparingly soluble in neat methanol or hexanes.

X-ray crystallography on alkynes $\mathbf{1 a , b}$ (Figure 1 and Figure $\mathrm{S} 1$ of Supporting Information) and on the ruthenium complex $\mathbf{2} \mathbf{a} \cdot \mathbf{2} \mathbf{C H}_{\mathbf{2}} \mathbf{C l}_{\mathbf{2}}$ (Figure 2) revealed the expected dimeric structures

(26) Maurer, J.; Sarkar, B.; Kaim, W.; Winter, R. F.; Záliš, S. Chem.-Eur. J. 2007, 13, 10257-10272.

(27) Maurer, J.; Sarkar, B.; Schwederski, B.; Kaim, W.; Winter, R. F.; Záliš, S. Organometallics 2006, 25, 3701-3712.

(28) Maurer, J.; Sarkar, B.; Zalis, S.; Winter, R. F. J. Solid State Electrochem. 2005, 9, 738-749. 
Scheme 1. Synthesis of the Hydrogen-Bonded Styryl Metal Complexes 2a,b and $\mathbf{3} \mathbf{a}, \mathbf{b}$

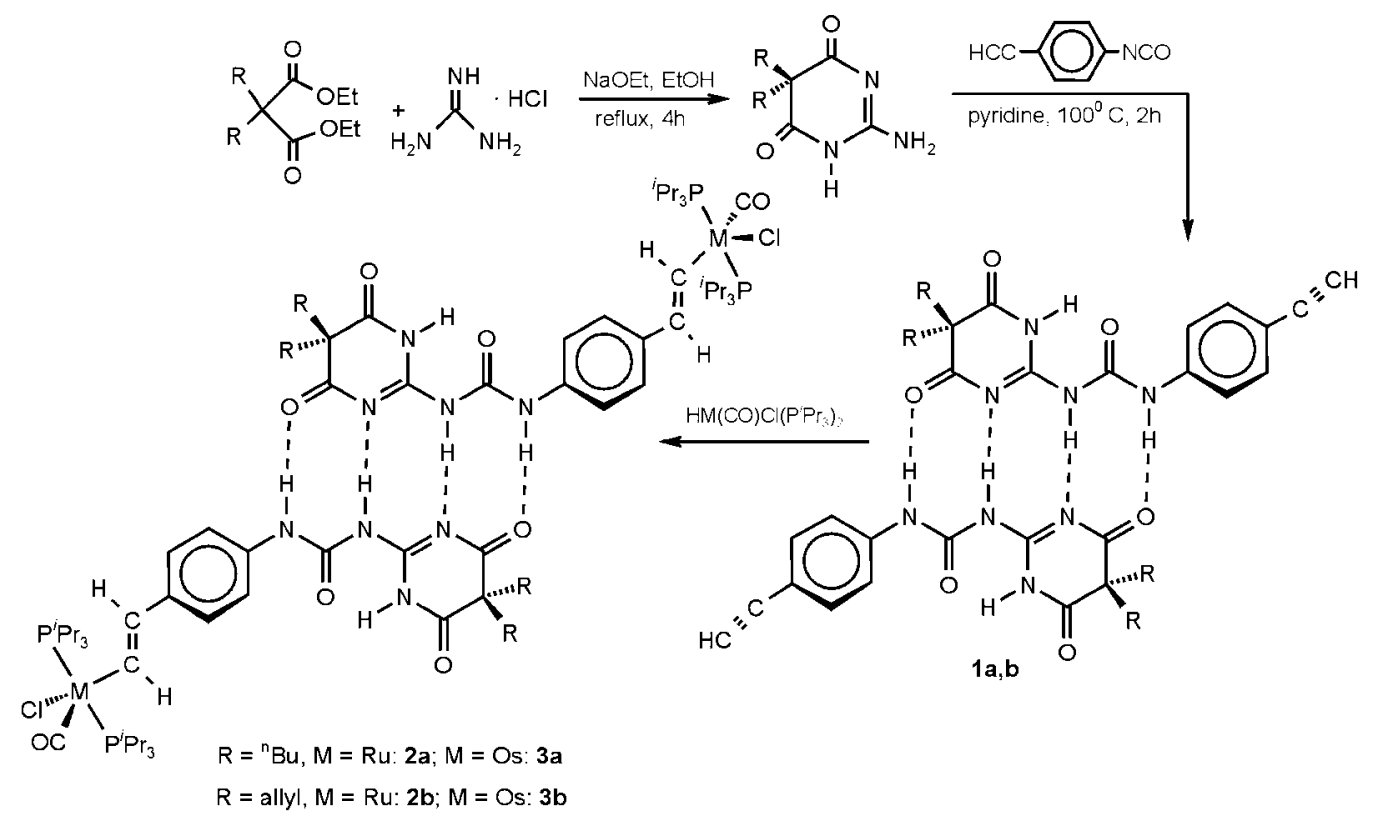

in the solid state. The centrosymmetric dimers are held together by four hydrogen bonds. Each $\mathrm{NH}$ proton of the urea function acts as a hydrogen-bond donor to either one imine nitrogen (pyrimidinedione-substituted $\mathrm{NH}$ ) or one carbonyl oxygen atom

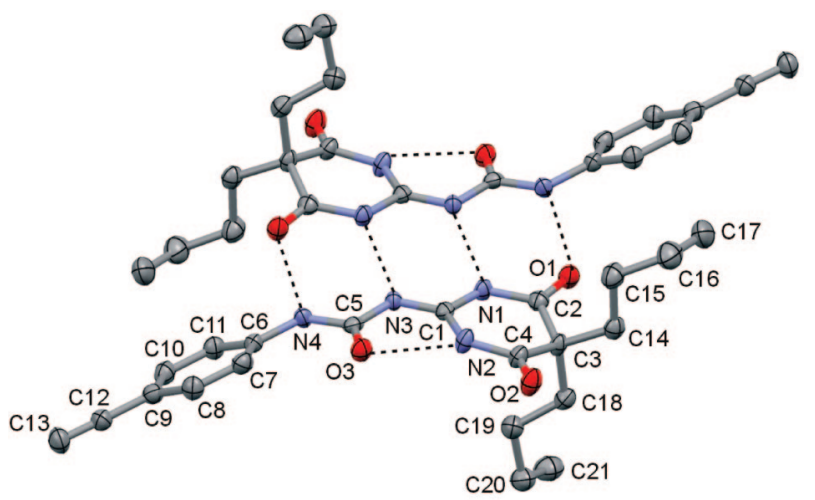

Figure 1. ORTEP plot of a dimer of alkyne 1a with ellipsoids set at a $50 \%$ probability level. Hydrogen atoms are omitted; intra- and intermolecular hydrogen bonds are indicated as dotted lines.

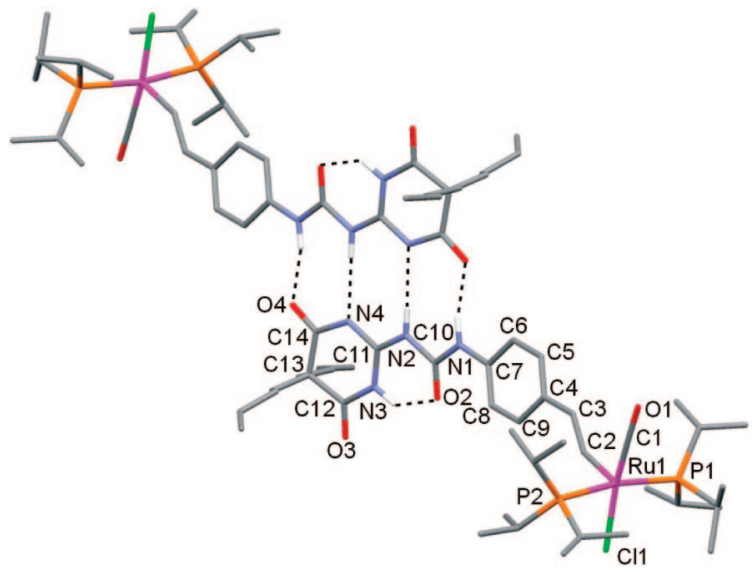

Figure 2. Capped sticks drawing of a dimer of complex 2a. Intra- and intermolecular hydrogen bonds are indicated as dotted lines. Hydrogen atoms except for those involved in hydrogen bonding have been omitted for clarity. (styryl-substituted $\mathrm{NH}$ ) of the pyrimidinedione ring of another molecule. Intradimer $N \mathrm{H} \cdots N=\mathrm{C}$ distances of $3.111 \AA$ in $\mathbf{1 a}$, 3.020 (molecule A) or $3.094 \AA$ (molecule B) of $\mathbf{1 b}$ and 3.124 $\AA$ in $2 \mathbf{a}$ are flanked by shorter $N \mathrm{H} \cdots O=\mathrm{C}$ distances of 2.850 $\AA$ in $\mathbf{1 a}, 2.823$ or $2.854 \AA$ in $\mathbf{1 b}$ and $2.863 \AA$ in $\mathbf{2 a}$. Strong hydrogen bonds of $2.598 \AA$ in $\mathbf{1 a}, 2.542$ or $2.551 \AA$ in $\mathbf{1 b}$ and $2.550 \AA$ in $\mathbf{2 a}$ between the remaining amide of the pyrimidinedione and the urea carbonyl of the same molecule are also observed. TherigidH-bonded scaffold fixes the ruthenium-ruthenium end-to-end distance within dimeric $2 \mathbf{a}$ to $24.56 \AA$. Intramolecular and intradimer hydrogen-bridging motifs of $\mathbf{1 a}, \mathbf{b}$ and $\mathbf{2 a}$ are identical to those in $\mathrm{N}$-alkyl-substituted 4,6-dioxo-5,5-dialkyland -5,5-dibenzyl-1,4,5,6-tetrahydropyrimidineurea derivatives. Intermolecular distances between the individual molecules of each dimer, however, tend to be somewhat longer as in aliphatic derivatives, where $d(N \mathrm{H} \cdots N=\mathrm{C})$ and $d(N \mathrm{H} \cdots O=\mathrm{C})$ values range from 2.921 to $3.030 \AA$ and from 2.746 to $2.877 \AA$, respectively. ${ }^{19}$

Of particular note are the interplanar angles between the 4-ethynylphenyl or the styryl ruthenium planes and that of the pyrimidinedione ring of $38.8^{\circ}(\mathbf{1 a}), 14.4^{\circ}$ or $9.5^{\circ}(\mathbf{1 b})$, or $18.9^{\circ}$ (2a), respectively. A nearly coplanar arrangement of the styryl ruthenium entity, the urea function, and the pyrimidinedione ring of $\mathbf{2 a}$ is a conformational prerequisite for communicating electronic information between the ruthenium styryl and the hydrogen-bonding moieties. Torsion angles $\mathrm{Ru}-\mathrm{C} 2-\mathrm{C} 3-\mathrm{C} 4$ of $172.9(7)^{\circ}, \mathrm{C} 2-\mathrm{C} 3-\mathrm{C} 4-\mathrm{C} 5$ of $-168.1(9)^{\circ}$ and C2-C3-C4-C9 of $13.3(14)^{\circ}$ further attest to $\pi$-conjugation within the ruthenium styryl moiety. The square pyramidal coordination of the metal atom and bonding parameters such as the $\mathrm{Ru}-\mathrm{C} 2$ (1.985(8) $\AA$ ),

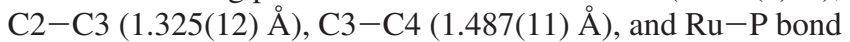
lengths of 2.394(2) $\AA$ and 2.396(2) $\AA$ as well as the P1-Ru-P2 and $\mathrm{Cl} 1-\mathrm{Ru}-\mathrm{C} 1$ bond angles of $169.58(8)^{\circ}$ and $171.8(3)^{\circ}$, respectively, are in the common range of five-coordinated ruthenium vinyl, alkyl, aryl, or hydride complexes and require no further comment. ${ }^{29-34}$ Torsion angles $\mathrm{Cl} 1-\mathrm{Ru}-\mathrm{C} 2-\mathrm{C} 3$ of $175.9(9)^{\circ}$ and $\mathrm{C} 1-\mathrm{Ru}-\mathrm{C} 2-\mathrm{C} 3$ of $-4.9(10)^{\circ}$ signal that the vinyl ligand resides in the $\mathrm{Cl1}-\mathrm{Ru}-\mathrm{C} 1$ plane. The ruthenium vinyl group bisects the $\mathrm{P} 1-\mathrm{Ru}-\mathrm{P} 2$ vector and forms a 


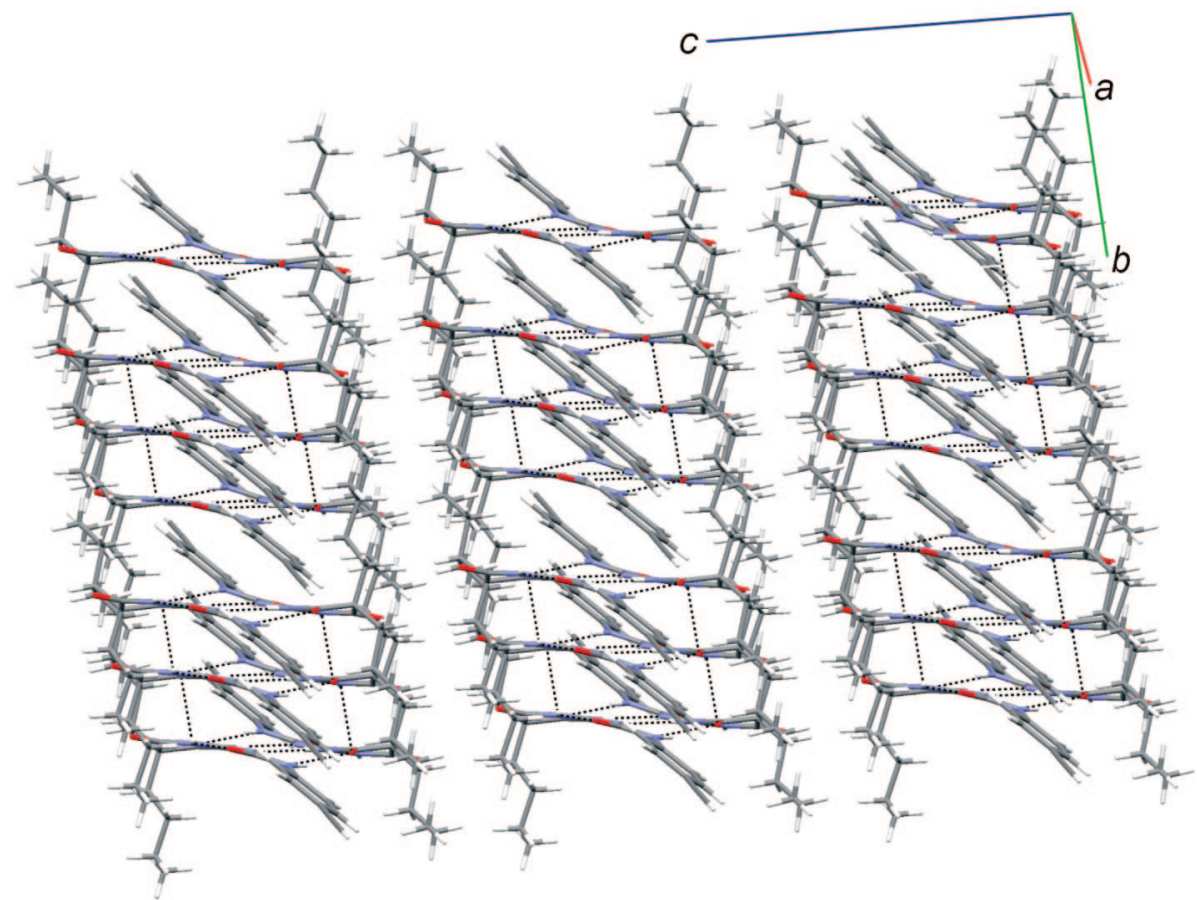

Figure 3. Packing of alkyne 1a in the crystal. Hydrogen bonds within and between individual dimers are indicated as dotted lines.

$\mathrm{P} 2-\mathrm{Ru}-\mathrm{C} 2-\mathrm{C} 3$ angle of $90.1(9)^{\circ}$ and a $\mathrm{P} 1-\mathrm{Ru}-\mathrm{C} 2-\mathrm{C} 3$ angle of $94.4(9)^{\circ}$ as it is routinely observed for such complexes.

Compounds $\mathbf{1 a}, \mathbf{b}$ and $\mathbf{2} \mathbf{a} \cdot \mathbf{2} \mathbf{C H}_{\mathbf{2}} \mathbf{C l}_{\mathbf{2}}$ also show interesting packing motifs in the crystal. Common is the further association of dimers into infinite chains via $\mathrm{NH} \cdots O=\mathrm{C}$ hydrogen bridges of $3.142 \AA$ (1a), $2.972 \AA$ (1) $)$, or $3.076 \AA$ (2a) between the pyrimidinedione amide N2 (1a), N7 of molecule B in 1b or N3 (2a), and the pyrimidinedione carbonyl $\mathrm{O} 2$ of $\mathbf{1 a}, \mathrm{O} 2$ of molecule A in 1b, or $\mathrm{O} 3$ of $\mathbf{2 a}$ (see Figures 3 and 4 and Figures S2 and S3 of the Supporting Information). These interdimer contacts always involve the imine nitrogen that already forms an intramolecular hydrogen bond to the urea carbonyl and the "backside" pyrimidinedione carbonyl that is not engaged in dimer formation. In 1a, staircase-like chains of interconnected dimers run parallel to the $a b$ plane, whereas in $\mathbf{1 b}$ a wavy arrangement of individual dimers along the chain propagation axis is observed. Interconnected dimers within the chains are tilted by about $30^{\circ}$ with respect to each other. In $\mathbf{2 a} \cdot \mathbf{2} \mathbf{C H}_{\mathbf{2}} \mathbf{C l}_{\mathbf{2}}$, staircase-like chains of parallel disposed dimers intersect at an angle of $43.5^{\circ}$. Additional $\mathrm{Ru}-\mathrm{Cl} \cdots \mathrm{H}_{2} \mathrm{CCl}_{2} \cdots \mathrm{HCCl}_{2} \mathrm{H} \cdots \mathrm{Cl}-\mathrm{Ru}$ and $\mathrm{Ru}-\mathrm{Cl} \cdots \mathrm{H}_{2} \mathrm{CCl}_{2} \cdots \mathrm{HCCl}_{2} \mathrm{H} \cdots \mathrm{O} \equiv \mathrm{C}-\mathrm{Ru}$ contacts interlink different chains. Each $\mathrm{Ru}-\mathrm{Cl}$ ligand hydrogen bonds to one $\mathrm{CH}$ of each of the crystallographically distinct $\mathrm{CH}_{2} \mathrm{Cl}_{2}$ molecules with $\mathrm{CH} \cdots \mathrm{Cl}$ distances of $2.562 \AA\left(\mathrm{CH}_{2} \mathrm{Cl}_{2}(1)\right)$ or $2.614 \AA\left(\mathrm{CH}_{2} \mathrm{Cl}_{2}(2)\right)$. The second hydrogen atom of $\mathrm{CH}_{2} \mathrm{Cl}_{2}(1)$ interacts weakly with the oxygen atom of the carbonyl ligand $(\mathrm{C}-\mathrm{H} \cdots \mathrm{O}=2.50 \AA)$,

(29) Maurer, J.; Linseis, M.; Sarkar, B.; Schwederski, B.; Niemeyer, M.; Kaim, W.; Záliš, S.; Anson, C.; Zabel, M; Winter, R. F. J. Am. Chem. Soc. 2009, 131, 259-268.

(30) Werner, H.; Esteruelas, M. A.; Otto, H. Organometallics 1986, 5, 2295.

(31) Huang, D.; Streib, W. E.; Bollinger, J. C.; Caulton, K. G.; Winter, R. F.; Scheiring, T. J. Am. Chem. Soc. 1999, 121, 8087-8097.

(32) Jung, S.; Ilg, K.; Brandt, C. D.; Wolf, J.; Werner, H. Eur. J. Inorg. Chem. 2004, 46, 9-480.

(33) Alcock, N. W.; Cartwright, J.; Hill, A. F.; Marcellin, M.; Rawles, H. M. J. Chem. Soc., Chem. Commun. 1995, 369-370.

(34) Maruyama, Y.; Yamamura, K.; Sagawa, T.; Katayama, H.; Ozawa, F. Organometallics 2000, 19, 1308-1318.

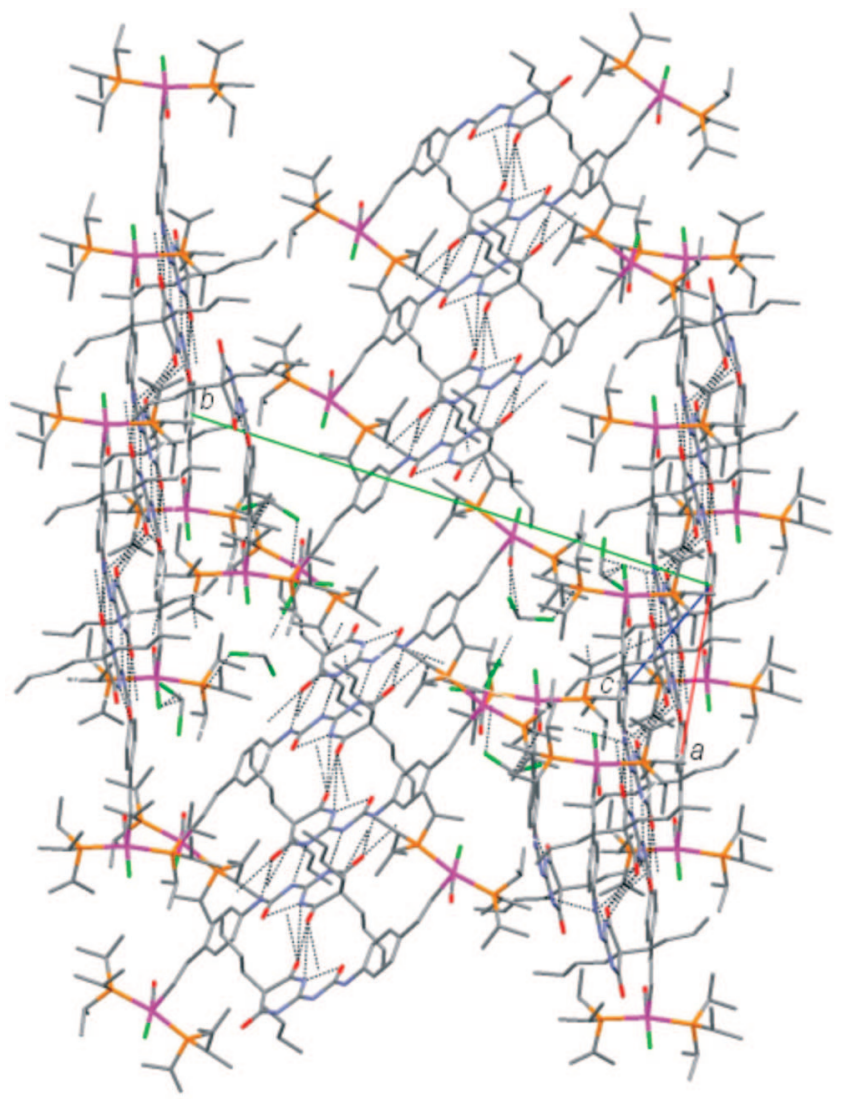

Figure 4. Packing of complex $\mathbf{2 a} \cdot \mathbf{2} \mathbf{C H}_{2} \mathbf{C l}_{\mathbf{2}}$ in the crystal. Intra- and intermolecular hydrogen bonds are indicated as dotted lines. Hydrogen atoms have been omitted for clarity.

while the second hydrogen atom of $\mathrm{CH}_{2} \mathrm{Cl}_{2}$ (2) forms a $\mathrm{CH} \cdots \mathrm{Cl}$ contact of $2.77 \AA$ with atom $\mathrm{Cl} 2$ on $\mathrm{CH}_{2} \mathrm{Cl}_{2}$ (1) (see Figure $\mathrm{S} 4$ of the Supporting Information). 


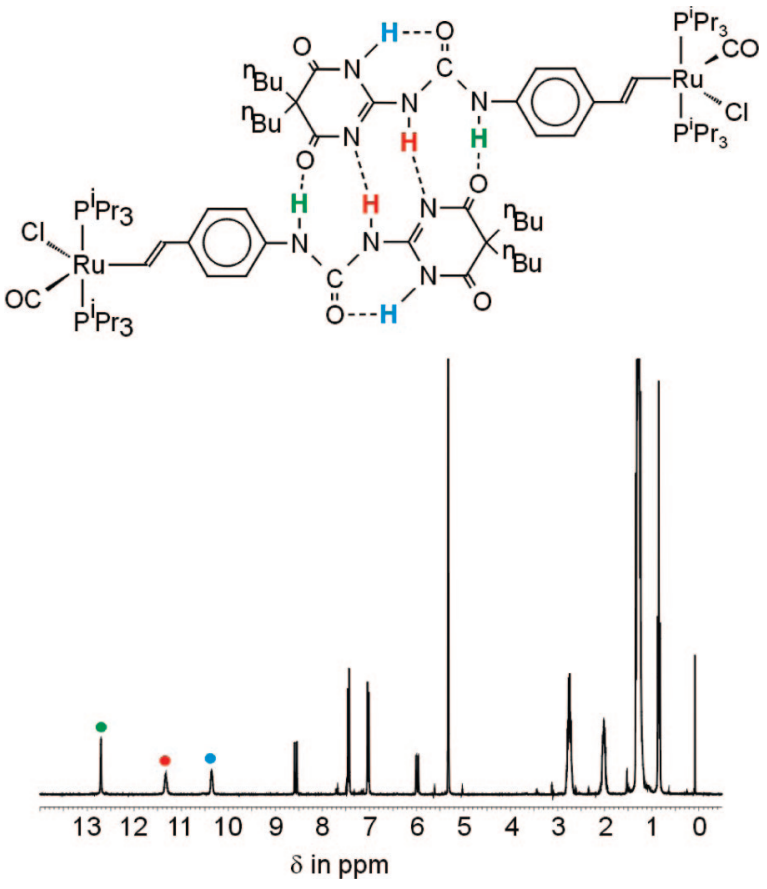

Figure 5. ${ }^{1} \mathrm{H}$ NMR spectrum of complex 2a in $\mathrm{CD}_{2} \mathrm{Cl}_{2}(293 \mathrm{~K}, c=1.1$ $\mathrm{mol} / \mathrm{L}$ ). Hydrogen atoms involved in hydrogen bonding are marked; the color coding corresponds to that in the chart at the top.

${ }^{1} \mathrm{H}$ NMR spectroscopy shows by virtue of the characteristic low-field shifts of the urea and imine hydrogen atoms engaged in the intramolecular and intradimer hydrogen bonding that the dimeric structures of the parent alkyne and its derived ruthenium and osmium vinyl complexes are maintained in $\mathrm{CD}_{2} \mathrm{Cl}_{2}$ and $\mathrm{CDCl}_{3}$ solutions. ${ }^{12}$ Proton signals in the respective spectral region were assigned by $\mathrm{HMBC}$ and $\mathrm{HSQC}$ measurements, which give $\delta(\mathrm{N} \underline{\mathrm{H}} \cdots \mathrm{OC}$, intermolecular $) \sim 12.7 \mathrm{ppm}, \mathrm{NH} \cdots \mathrm{N}$ (intermolecular) $\sim 11.5 \mathrm{ppm}$, and $\delta$ ( $\mathrm{NH} \cdots \mathrm{OC}$, intramolecular) $\sim 10.5 \mathrm{ppm}$ (see Figure 5). The latter proton (blue color in Figure 5 ) easily exchanges with the inner urea proton (red color) and much more slowly with the outer urea proton (green color in Figure 5) as follows from these NMR experiments. The former process involves tautomerization of the urea $\mathrm{NH}$ and the imine $\mathrm{N}$ groups and rotation of the tetrahydropyrimidine ring. All these signals appear at much lower field than in nonassociated alkyl or aryl urea derivatives. ${ }^{12}$ This is also true for $\mathrm{CD}_{2} \mathrm{Cl}_{2}$ solutions in the presence of a large excess of $\mathrm{NBu}_{4} \mathrm{PF}_{6}$ and at concentrations $(1.1 \mathrm{mM}$ in the complex, $0.1 \mathrm{M}$ in the supporting electrolyte) as they are typically employed in voltammetry (see Figure S5 of the Supporting Information). Addition of $\mathrm{CD}_{3} \mathrm{OH}$ to $\mathrm{CD}_{2} \mathrm{Cl}_{2}$ solutions leads to broadening and appreciable highfield shifts of the $=\mathrm{NH}$ signals, which accounts for the anticipated interference of that solvent with hydrogen bonding. In agreement with observations on similar systems, ${ }^{35-37}{ }^{1} \mathrm{H}$ NMR spectra of alkynes $\mathbf{1 a}, \mathbf{b}$ in $\mathrm{CD}_{3} \mathrm{CN}$ display $\mathrm{NH}$ shifts very similar to those in $\mathrm{CDCl}_{3}$ or $\mathrm{CD}_{2} \mathrm{Cl}_{2}$ which argues against interference of the weakly hydrogen-bond-donating ${ }^{38-40}$ and moderately hydrogen-bond-accepting acetonitrile solvent $t^{38,39}$

(35) Sharif, S.; Denisov, G. S.; Toney, M. D.; Limbach, H.-H. J. Am. Chem. Soc. 2007, 129, 6313-6327.

(36) Pérez, E. M.; Dryden, D. T. F.; Leigh, D. A.; Teobaldi, G.; Zerbetto, F. J. Am. Chem. Soc. 2004, 126, 12210-12211.

(37) Bohne, C.; Ihmels, H.; Waidelich, M.; Yihwa, C. J. Am. Chem. Soc. 2005, 127, 17158-17159.

(38) Marcus, Y. Chem. Soc. Rev. 1993, 22, 409-416.

(39) Abraham, M. H. Chem. Soc. Rev. 1993, 22, 73-83. a)
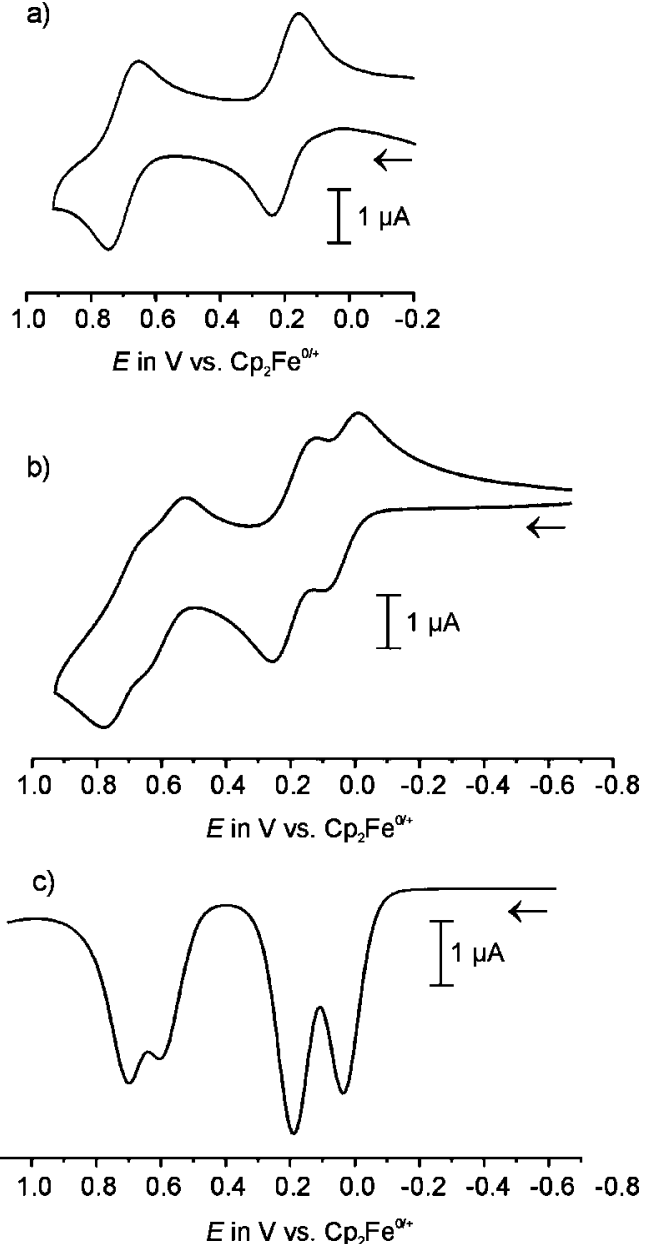

Figure 6. (a) Voltammogram of a $0.17 \mathrm{mM}$ solution of complex 2a in $\mathrm{CH}_{2} \mathrm{Cl}_{2} / \mathrm{NBu}_{4} \mathrm{PF}_{6}(0.1 \mathrm{M})$ at $\mathrm{rt}$ and $v=0.1 \mathrm{~V} / \mathrm{s}$. (b) Voltammogram of a mixture of $\mathbf{2 a}$ and $\mathbf{3 b}$ in $\mathrm{CH}_{2} \mathrm{Cl}_{2} / \mathrm{NBu}_{4} \mathrm{PF}_{6}(0.1 \mathrm{M})$ at $\mathrm{rt}$ and $v=0.1 \mathrm{~V} / \mathrm{s}$ after $20 \mathrm{~h}$ of equilibration. (c) Square wave voltammogram of the solution as in (b) $(v=15 \mathrm{~Hz})$.

with dimerization via four hydrogen bonds. Fast solvolysis of the metal $-\mathrm{Cl}$ bond of complexes $\mathbf{2 a}, \mathbf{b}$ and $\mathbf{3 a}, \mathbf{b}$ does not allow us to record their NMR spectra in $\mathrm{CD}_{3} \mathrm{CN}$ solvent.

Electrochemical investigations on the hydrogen-bonded dimers of $\mathbf{2} \mathbf{a}, \mathbf{b}$ and $\mathbf{3 a}, \mathbf{b}$ were performed in $\mathrm{CH}_{2} \mathrm{Cl}_{2} / 0.1 \mathrm{M} \mathrm{NBu}_{4} \mathrm{PF}_{6}$ as the electrolyte. Each complex undergoes two consecutive oxidations. The first wave is chemically reversible, but the second one is only partially so with reversibility coefficients in the range of $0.76-0.90$ at $0.1 \mathrm{~V} / \mathrm{s}$. Half-wave potential separations are in the range of 515-530 $\mathrm{mV}$ (Figure 6a). Both waves are somewhat broader as would be expected of a fast uncomplicated one-electron process as it is shown by the larger peakto-peak separations and half-widths of the forward (anodic) peak when compared to the internal decamethylferrrocene standard. Digital simulations of the experimental voltammograms ${ }^{41}$ are most consistent with somewhat sluggish electron-transfer kinetics (electron-transfer rates $k_{\mathrm{ET}} \approx 0.005 \mathrm{~cm}^{-1}$ and $0.0038 \mathrm{~cm} \cdot \mathrm{s}^{-1}$ for the first and second oxidation, respectively). ${ }^{42}$ The osmium complexes 3a,b are oxidized at $\sim 175 \mathrm{mV}$ lower potential than their ruthenium congeners $\mathbf{2 a}, \mathbf{b}$. Redox potentials and peak-topeak separations are listed in Table 1.

(40) Stolov, A. A.; Kamalova, D. I.; Borisover, M. D.; Solomonov, B. N.; Remizov, A. R. Spectrochim. Acta 1994, 50A, 145-150.

(41) Rudolph, M.; Feldberg, S. DigiSim3, Version 3.03, Bioanalytical Systems, Inc.:West Lafayette, IN, 1994. 
Table 1. Data Pertinent to Electrochemical Investigations on Vinyl Complexes $\mathbf{2 a}, \mathbf{b}, \mathbf{3} \mathbf{a}, \mathbf{b}$ and $\mathbf{5}$ at $v=100 \mathrm{mV} / \mathrm{s}$

\begin{tabular}{lcccrl}
\hline cmpd & $\begin{array}{c}E_{1 / 2}{ }^{1 /+} \\
\text { in } \mathrm{V}\end{array}$ & $\begin{array}{c}E_{\mathrm{p}, \mathrm{f}}-E_{\mathrm{p}, \mathrm{f} / 2} / \\
\Delta E_{\mathrm{p}} \text { in } \mathrm{mV}\end{array}$ & $\begin{array}{c}E_{1 / 2}{ }^{0 /+} \\
\text { in } \mathrm{V}\end{array}$ & $\begin{array}{r}E_{\mathrm{p}, \mathrm{f}}-E_{\mathrm{p}, \mathrm{f} / 2} / \\
\Delta E_{\mathrm{p}} \text { in } \mathrm{mV}\end{array}$ & $D$ in $10^{-9} \mathrm{~m}^{2} \cdot \mathrm{s}^{-1}$ \\
\hline $\mathbf{2 a}$ & 0.19 & $63 / 76$ & 0.71 & $61 / 75$ & $0.55(7)$ \\
$\mathbf{2 b}$ & 0.195 & $60 / 80$ & 0.70 & $60 / 80$ & not measured \\
$\mathbf{3 a}$ & 0.020 & $68 / 94$ & 0.550 & $104 / 136$ & not measured \\
$\mathbf{3 b}$ & 0.015 & $58 / 79$ & 0.540 & $70 / 109$ & not measured \\
$\mathbf{5}$ & 0.085 & $57 / 59$ & 0.60 & $58 / 60$ & $0.70(3)$ \\
\hline
\end{tabular}

The overall wave pattern is largely invariant to the addition of methanol which breaks the intermolecular hydrogen bonds as follows from ${ }^{1} \mathrm{H}$ NMR spectroscopy. The only effects were the partial loss of chemical reversibility, broadening of particularly the second wave and its final disappearance into the solvent background when more methanol was added (Figure S6 of the Supporting Information). This contrasts to observations by Kaifer et al. on the related ferrocenyl system where the two waves in $\mathrm{CH}_{2} \mathrm{Cl}_{2} / \mathrm{NBu}_{4} \mathrm{PF}_{6}$ evolved into a single one upon addition of even the weakly hydrogen-bonding acetonitrile. ${ }^{23}$ Addition of the osmium complex $\mathbf{3 b}$ to the ruthenium complex 2a results in rapid scrambling and the formation of a mixture of dimers $(\mathbf{2} \mathbf{a})_{2}, \mathbf{2 a} / \mathbf{3 b}$ and $(\mathbf{3 b})_{2}$ as was ascertained by ${ }^{1} \mathrm{H}$ NMR spectroscopy. At $T=203 \mathrm{~K}$ scrambling is sufficiently slow so that a separate set of resonance signals can be observed for the mixed $\mathbf{2 a / 3 b}$ dimer (see Figure S7 of the Supporting Information). Such solutions still showed only the two separated pairs of waves (cyclic voltammetry) or peaks (square wave voltammetry) at the same potentials as the pure complexes $(\mathbf{2 a})_{2}$ and $(3 b)_{2}$ (Figure $\left.6 b, c\right)$ but neither a new pair of waves/peaks nor a potential shift that might be expected of a mixed dimer $\mathbf{2 a} / \mathbf{3 b}$ if the two subunits were interacting.

Comparison of the slopes from $i$ vs $t^{1 / 2}$ plots in chronoamperometry and of the step heights in steady-state voltammetry to those of the decamethylferrocene standard according to the method of Baranski ${ }^{43}$ finally established that each voltammetric wave of complexes $\mathbf{2 a}, \mathbf{b}$ and $\mathbf{3 a}, \mathbf{b}$ involves the loss of two electrons per ruthenium or osmium dimer. In addition, combined chronocoulometry (CC) and linear sweep voltammetry (LSV) data on $(\mathbf{2 a})_{2}$ and $(\mathbf{3 a})_{2}$ are only consistent with the transfer of one electron for every styryl ruthenium subunit. Assuming that each wave involves the transfer of one electron per dimer would give the unrealistic result that these complexes have a diffusion coefficient similar to that of ferrocene. Furthermore, diffusion coefficients determined by CC and LSV would differ by a factor of 2. We therefore conclude that the Upy-bridged dimeric styryl complexes do not exhibit any electrochemically detectable electronic coupling between the individual styryl metal subunits.

Wave splittings in electrochemical measurements are one first indicator, but are not wholly conclusive for the efficacy of electronic coupling between bridged redox sites in mixed-valent systems. ${ }^{28,44,45} \mathrm{We}$ therefore utilized the oxidation-state sensitive spectroscopic tags of the complexes $\mathbf{2} \mathbf{a}, \mathbf{b}$ and $\mathbf{3 a}, \mathbf{b}$ to independently probe for such interactions and for charge delocalization. When the first oxidation of hydrogen-bonded dimers $(\mathbf{2 a})_{2}$ and $(\mathbf{2 b})_{2}$ was followed inside an optically transparent thin-layer

(42) The alternative model of two closely spaced one-electron waves is only compatible with a splitting of less than $35 \mathrm{mV}$ between the $0 /+$ and $+/ 2+$ waves and gives a less accurate fit.

(43) Baranski, A. S.; Fawcett, W. R.; Gilbert, C. M. Anal. Chem. 1985, 57, 166-170.

(44) Barrière, F.; Geiger, W. E. J. Am. Chem. Soc. 2006, 128, 3980-3989.

(45) Glöckle, M.; Kaim, W.; Fiedler, J. Organometallics 1998, 17, 49234925. electrolysis cell, the single band of the metal-carbonyl stretch shifted from 1912 to $1967 \mathrm{~cm}^{-1}$ without any detectable intermediate (Table 3, Figure 7, and Figure S8 of the Supporting Information). The $\mathrm{Ru}-\mathrm{CO}$ band shift upon oxidation is a highly sensitive measure of the loss of electron density from the metal. As the electron density at the metal atom decreases, metal backdonation into the $\mathrm{CO} \pi^{*}$ orbitals is weakened. This in turn strengthens the $\mathrm{CO}$ bond and shifts the $\mathrm{CO}$ band to higher energy. Redox couples $\mathrm{Ru}\left(\mathrm{PR}_{3}\right)_{2}(\mathrm{CO})_{3}{ }^{0 /+}$ display oxidationinduced $\mathrm{CO}$ band shifts of about $120-130 \mathrm{~cm}^{-1}$ and provide benchmark systems for the effects of a largely metal-centered oxidation in ruthenium chemistry. ${ }^{46}$ Large styryl ligand contributions of about $70 \%$ to the HOMO in the complex $(\mathrm{CO}) \mathrm{Cl}\left(\mathrm{P}^{i} \mathrm{Pr}_{3}\right)_{2} \mathrm{Ru}(\mathrm{CH}=\mathrm{CHPh})$ lead to an appreciably smaller $\mathrm{CO}$ band shift of $65 \mathrm{~cm}^{-1}$ upon one-electron oxidation. ${ }^{29}$ The $55 \mathrm{~cm}^{-1}$ shift observed for complexes $\mathbf{2 a}$, b closely resembles this value, but signals an even larger ligand contribution in the urea-substituted system. The somewhat lower CO band shift compared to the unsubstituted styryl complex is readily explained by the electron-donating property of the urea substituent at the para position which further aids in charge delocalization. The osmium complexes 3a,b show slightly lower absolute $\tilde{v}(\mathrm{CO})$ shifts but give otherwise identical results (Table 3 ).

Other IR spectroscopic effects include slight red-shifts of the multiple $\mathrm{NH}$ bands that originate from the hydrogen-bonded imine groups and intensity changes but hardly any shift of the associated higher-energy urea and pyrimidinedione carbonyl bands (see Figures 7 and Figures S8 and S9 of the Supporting Information). Stronger changes in the region below $1600 \mathrm{~cm}^{-1}$ cannot unambiguously be assigned due to the close proximity of the $\mathrm{CNH}$ stretching and bending modes with the $\mathrm{C}=\mathrm{C}$ stretch of the ruthenium styryl moiety. Vibrational data in various oxidation states and tentative assignments based on literature values for pyrimidine-4,6-diones, ${ }^{47}$ ureas, ${ }^{48}$ and styryl complexes ${ }^{27,29}$ and on our quantum chemical calculations (vide infra) are collected in Tables 2, 3, and 5 .

The effects of the second oxidation were exemplarily studied with complex $\mathbf{2 b}$. The most notable feature is the further blueshift of the $\mathrm{Ru}-\mathrm{CO}$ band to $1990 \mathrm{~cm}^{-1}$ (Table 3). The small CO band shift of only $23 \mathrm{~cm}^{-1}$ signals that the second oxidation is also dominated by the styryl ligand with an even smaller contribution of the metal atom. This parallels our results on pyrenylvinyl complexes $\left(\mathrm{PR}_{3}\right)_{2}(\mathrm{~L})(\mathrm{CO}) \mathrm{ClRu}(\mathrm{CH}=\mathrm{CH}$-2-pyrenyl) $\left(\mathrm{R}={ }^{i} \mathrm{Pr}, \mathrm{L}=\right.$ none; $\mathrm{R}=\mathrm{Ph}, \mathrm{L}=$ isonicotinate $) .{ }^{25}$

The neutral complexes $\mathbf{2} \mathbf{a}, \mathbf{b}$ and $\mathbf{3} \mathbf{a}, \mathbf{b}$ feature intense electronic bands at $\sim 265,297$, and $360 \mathrm{~nm}$ that are assigned to intraligand $\pi \rightarrow \pi^{*}$ and ligand-to-metal charge-transfer (LMCT) or mixed intraligand and metal-to-ligand charge transfer (ILCT)/ MLCT absorptions (see Table S7 and Figure S16 of the Supporting Information), respectively, and a weak band near $520 \mathrm{~nm}$ due to a forbidden transition within the d-manifold that is characteristic of $\mathrm{d}^{6} \mathrm{ML}_{5}$ complexes. ${ }^{49,50}$ This pattern is very similar to that of related styryl complexes and thus seems unperturbed by hydrogen bonding. UV/vis/NIR spectroelectro-

(46) Sherlock, S. J.; Boyd, D. C.; Moasser, B.; Gladfelter, W. L. Inorg. Chem. 1991, 20, 3626-3632.

(47) Ahluwalia, V. K.; Sharma, S.; Kaur, M. Spectrochim. Acta 1989, 45A, 917-927.

(48) Lin-Vien, D.; Colthup, N. B.; Fateley, W. G.; Grasselli, J. G. The Handbook of Infrared and Raman Characteristic Frequencies of Organic Molecules; Academic Press: San Diego, 1991.

(49) Bressan, M.; Rigo, P. Inorg. Chem. 1975, 14, 2286-2288.

(50) Briggs, J. C.; McAuliffe, C. A.; Dyer, G. J. Chem. Soc., Dalton Trans. 1984, 423-427. 
Table 3. IR Spectra of $\mathbf{2 a , b}$, and $\mathbf{3} \mathbf{b}$ in the Neutral and the Monooxidized State and of $\mathbf{2} \mathbf{b}^{\mathbf{2}+}\left(\tilde{v}\right.$ in $\left.\mathrm{cm}^{-1}\right)$

\begin{tabular}{|c|c|c|c|c|c|c|c|}
\hline & $2 a$ & $2 a^{+}$ & $2 b$ & $2 b^{+}$ & $2 b^{2+}$ & $3 b$ & $3 b^{+}$ \\
\hline$v(\mathrm{NH})$ & $\begin{array}{l}3412,3289,3260 \\
3179,3100\end{array}$ & $\begin{array}{l}3380,3276,3230 \\
3184,3152,3096\end{array}$ & $3397,3288,3180$ & $\begin{array}{l}3378,3284,3193, \\
3147\end{array}$ & $3384,3319,3201$ & & \\
\hline$v(\mathrm{CO})$ & 1912 & 1967 & 1912 & 1967 & 1990 & 1894 & 1945 \\
\hline $\begin{array}{l}v(\mathrm{CO})_{\text {pmd, as }} \\
+\delta(\mathrm{CNH})_{\text {urea }}\end{array}$ & 1703 & 1703 & 1706 & 1706 & 1742 & 1707 & 1705 \\
\hline$v(\mathrm{CO})_{\text {pmd, as }}$ & 1667 & 1668 & 1663 & 1667 & 1651 & 1660 & 1665 \\
\hline$+\delta(\mathrm{CNH})_{\text {urea }}$ & 1648 & 1648 & 1650,1643 & 1649,1643 & 1641 & & \\
\hline $\begin{array}{l}\delta(\mathrm{CNH})_{\text {urea }} \\
+\delta(\mathrm{CNH})_{\mathrm{pmd}}\end{array}$ & $1525,1507,1483$ & 1513,1483 & $1509,1483,1471$ & $\begin{array}{l}1525,1507,1483, \\
1471\end{array}$ & 1528 & 1508 & 1512 \\
\hline
\end{tabular}

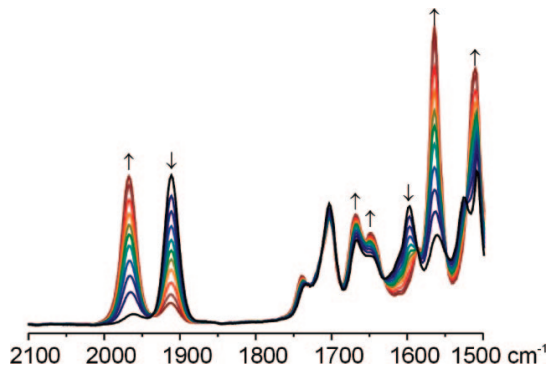

Figure 7. IR spectroelectrochemistry on complex $\mathbf{2 a}\left(\mathrm{DCE} / \mathrm{NBu}_{4} \mathrm{PF}_{6}, \mathrm{rt}\right)$ in the carbonyl, $\mathrm{C}=\mathrm{N}$ and $\mathrm{C}=\mathrm{C}$ regions. Spectroscopic changes during the first oxidation.

Table 2. IR Spectra of Alkynes $\mathbf{1 a , b}$ and 4 and of Complex 5 ( $\tilde{v}$ in $\mathrm{cm}^{-1}$ ) in the Neutral and the Monooxidized State and Calculated Data for the Upy ${ }^{\mathrm{Me}}$ Monomer and Dimeric $\left(\mathrm{Upy}^{\mathrm{Me}}\right)_{2}{ }^{a}$

\begin{tabular}{|c|c|c|c|c|c|c|c|}
\hline & $1 a$ & $1 \mathrm{~b}$ & 4 & 5 & $5^{+}$ & $\left(\mathrm{Upy}^{\mathrm{Me}}\right)_{2}$ & Upy ${ }^{\mathrm{Me}}$ \\
\hline$v(\mathrm{CO})$ & - & - & - & 1910 & 1964 & - & - \\
\hline$v(\equiv \mathrm{CH})$ & 3300 & 3290 & 3290 & - & - & - & - \\
\hline$v(\mathrm{C} \equiv \mathrm{C})$ & 2107 & 2105 & 2106 & & & & \\
\hline$v(\mathrm{CO})_{\text {pmd, as }}$ & 1735 & 1734 & - & - & - & 1747 & 1748 \\
\hline $\begin{array}{l}v(\mathrm{CO})_{\text {pmd, as }} \\
+\delta(\mathrm{CNH})_{\text {urea }}\end{array}$ & 1703 & 1702 & - & 1722 & 1722 & 1715 & 1715 \\
\hline $\begin{array}{l}v(\mathrm{CO})_{\mathrm{pmd}, \text { as }} \\
+\delta(\mathrm{CNH})_{\text {urea }}\end{array}$ & 1671 & 1665 & 1635 & & & 1658 & 1707 \\
\hline$\delta(\mathrm{CNH})_{\text {urea }}$ & 1592 & 1592 & 1587 & 1591 & 1581 & 1613 & 1603 \\
\hline $\begin{array}{l}+\delta(\mathrm{CNH})_{\text {pmd }} \\
{\left[+\delta(\mathrm{C}=\mathrm{C})_{\text {styryl }}\right.}\end{array}$ & & & 1559 & 1562 & 1572 & 1568 & 1531 \\
\hline$\delta(\mathrm{CNH})_{\text {urea }}$ & 1528 & 1528 & 1505 & & 1514 & 1527 & 1495 \\
\hline$+\delta(\mathrm{CNH})_{\mathrm{pmd}}$ & 1509 & 1508 & & & & & \\
\hline
\end{tabular}

${ }^{a}$ DFT/B3LYP calculated energies are scaled by the factor 0.957 .

chemistry revealed the appearance of a split absorption near $430 \mathrm{~nm}$ and a lower-energy absorption band peaking at $\sim 700$ $\mathrm{nm}$ upon the first oxidation (Figure 8). Such bands are routinely observed for the radical cations of styryl ruthenium complexes and involve a $\pi \rightarrow \pi^{*}$ transition within the oxidized metal styryl chromophore $(\beta \mathrm{HOMO} \rightarrow \beta$ LUMO, calculated energy $1.81 \mathrm{eV}$, $\lambda=684 \mathrm{~nm}$ ) and nearly degenerate ILCT and metal-to-ligand charge transfer (MLCT) transitions $(\alpha \mathrm{HOMO} \rightarrow \alpha \mathrm{LUMO}+1$ and $\beta \mathrm{HOMO}-8 \rightarrow \beta$ LUMO, calculated energies 3.04 and $3.05 \mathrm{eV}$, $\lambda=408$ and $406 \mathrm{~nm}$ ) as well as a close-lying strongly mixed transition calculated at $3.14 \mathrm{eV}(395 \mathrm{~nm}$, see Table S8 and Figure S17 of the Supporting Information).

Partial in situ oxidation of a solution of complex 2a inside an ESR tube provided a solution that was ESR silent in fluid solution but revealed a weak signal in a frozen matrix at $110 \mathrm{~K}$ at $g=2.033$ which again is in the typical range of styryl ruthenium radical cations.

The Urea-Substituted Styryl Complex 5. It is now of interest to compare the strongly hydrogen-bonded complexes $\mathbf{2 a}, \mathbf{b}$ and 3a,b with similarly substituted styryl complexes that will not dimerize in solution. To these ends we prepared $N$-phenyl- $N^{\prime}(4-$ ethynylphenyl)urea (4, Chart 2 ) and converted it to the ruthenium vinyl complex 5. ${ }^{1} \mathrm{H}$ NMR spectroscopy showed the $\mathrm{NH}$ proton signals of the urea moiety at $\sim 7 \mathrm{ppm}$ and thus at considerably higher field than in the dimers of $\mathbf{2 a}, \mathbf{b}$ and $\mathbf{3 a}, \mathbf{b}$.

$\mathrm{X}$-ray crystallographic investigations on alkyne $\mathbf{4}$ and complex 5 disclosed association through hydrogen bonding involving the urea functions in crystalline $\mathbf{4}$, but not in complex $\mathbf{5}$. Hydrogen bridges between the $\mathrm{NH}$ protons and the urea carbonyl assemble individual molecules of alkyne $\mathbf{4}$ into one-dimensional infinite chains that run along the crystallographic $a$ axis (Figure 9). $N \mathrm{H} \cdots O=\mathrm{C}$ distances between the two crystallographically independent molecules of $\mathbf{4}$ range from 2.856 to $2.885 \AA$. The aryl rings of each molecule are almost perpendicular to each other with angles of $87.6^{\circ}$ or $88.4^{\circ}$ between their best planes. $\mathrm{CH} \cdots \mathrm{C}=\mathrm{C}_{\text {arene }}$ interactions $\mathrm{H} 5 \cdots \mathrm{C} 1(2.869 \AA), \mathrm{H} 5 \cdots \mathrm{C} 2(2.750$ $\AA), \quad \mathrm{H} 25 \cdots \mathrm{C} 21 \quad(2.876 \AA), \quad \mathrm{H} 25 \cdots \mathrm{C} 22(2.763 \AA)$ and CH $\cdots \mathrm{C}_{\text {arene }}$ interactions H8 $\cdots \mathrm{C} 11(2.891 \AA), \mathrm{H} 11 \cdots \mathrm{C} 8(2.849$ $\AA), \mathrm{H} 29 \cdots \mathrm{C} 32(2.853 \AA), \mathrm{H} 32 \cdots \mathrm{C} 29(2.879 \AA)$ between perpendicular arene rings interconnect these chains to infinite stacks. These stacks are arranged in an antiparallel fashion. Individual molecules belonging to different stacks tilt at an angle of about $59^{\circ}$ or $122^{\circ}$ with respect to the crystallographic $b$ axis. This generates a fishbone pattern that propagates along the $c$ axis (Figure S11 of the Supporting Information). The alkynyl groups of a stack point in the same direction and toward those of a neighboring stack. This allows for additional weak contacts between the acetylenic hydrogen atom H35 and alkyne carbon atoms C14 and C15 of 2.966 or $2.964 \AA$.

In complex $\mathbf{5}$, none of these interactions is preserved. Rather, hydrogen bonds between the chloride ligand and both $\mathrm{NH}$ functions of the immediate neighbor molecule with $\mathrm{NH} \cdots \mathrm{Cl}$ distances of $2.53 \AA$ and $2.76 \AA$ for two molecules A or $2.42 \AA$ and $2.72 \AA$ for two molecules B lead to an alternative mode of association into weakly bonded dimers (Figure 10). These hydrogen-bonding interactions are very likely not maintained in solution as follows from the $\mathrm{NH}$ proton shifts. In the crystal, dimers of molecules A and B form a criss-cross pattern parallel to the $a c$ plane and are only weakly connected by $\mathrm{H} \cdots \mathrm{O}$ contacts of $2.54 \AA$ between the carbonyl ligand and $\mathrm{H}(23)$ of the styryl ligand (see Figure S12 of the Supporting Information).

Individual molecules A and B of $\mathbf{5}$ have similar metrical parameters in the vicinity of the metal atom but differ somewhat with respect to the styryl urea moiety. The most notable differences pertain to the vinyl group where the short-long alternation of molecule $\mathrm{A}$ with $\mathrm{C}=\mathrm{C}$ and $=\mathrm{C}-\mathrm{C}$ bond lengths of 1.246(13) $\AA$ and 1.496(17) $\AA$, respectively, is more pronounced than for molecule B (1.302(11) $\AA$ and 1.429(15) $\AA$ ), 
Table 5. DFT/B3LYP Calculated Vibration Energies $\left(\tilde{v}\right.$ in $\left.\mathrm{cm}^{-1}\right)$ for $\mathbf{2}^{\mathrm{Me}}, \mathbf{3}^{\mathrm{Me}}$, and $\mathbf{5}^{\mathrm{Me}}$ Model Complexes in the Neutral and Oxidized States ${ }^{a}$

\begin{tabular}{|c|c|c|c|c|c|c|c|}
\hline & $2^{\mathrm{Me}}$ & $2^{\mathrm{Me} \cdot+}$ & $2^{\text {Me } 2+}$ & $3^{\mathrm{Me}}$ & $3^{\mathrm{Me} \cdot+}$ & $5^{\mathrm{Me}}$ & $5^{\mathrm{Me} \cdot+}$ \\
\hline$v(\mathrm{CO})$ & 1912 & 1956 & 1993 & 1900 & 1943 & 1911 & 1952 \\
\hline$v(\mathrm{CO})_{\text {pmd, as }}$ & 1767 & 1777 & 1792 & 1767 & 1776 & - & \\
\hline$v(\mathrm{CO})_{\text {pmd, as }}+\delta(\mathrm{CNH})_{\text {urea }}$ & 1751 & 1762 & 1768 & 1751 & 1762 & - & \\
\hline \multirow{2}{*}{$\delta(\mathrm{CNH})_{\text {urea }}+\delta(\mathrm{CNH})_{\text {pmd }}\left[+\delta(\mathrm{C}=\mathrm{C})_{\text {styryl }}\right]$} & 1610 & 1618 & 1614 & 1609 & 1618 & 1571 & 1592 \\
\hline & 1567 & 1585 & & 1569 & 1584 & 1555 & 1584 \\
\hline$\delta(\mathrm{CNH})_{\text {urea }}+\delta(\mathrm{CNH})_{\mathrm{pmd}}$ & 1500 & 1535 & 1599 & 1500 & 1536 & 1500 & 1510 \\
\hline
\end{tabular}

${ }^{a}$ Calculated frequencies are scaled by the factor 0.957 .

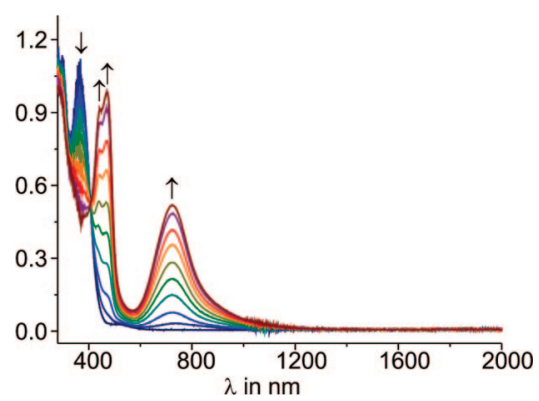

Figure 8. UV/vis/NIR spectroelectrochemistry on complex 2b (DCE/ $\mathrm{NBu}_{4} \mathrm{PF}_{6}, \mathrm{rt}$ ). Spectroscopic changes during the first oxidation.

Chart 2. Phenylureyl-Substituted Alkyne 4 and Styryl Complex 5
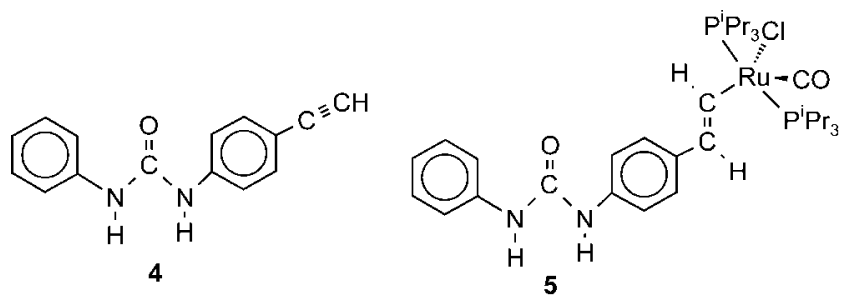

and to the vicinity of the urea carbonyl $\mathrm{C}$ atom, which shows more dissimilar OC $-\mathrm{N}$ bond lengths of 1.329(15) $\AA$ and 1.433(13) $\AA$ for molecule $B$ than for molecule $A$, where values of 1.365(15) $\AA$ and 1.392(12) $\AA$ are found. The longer $\mathrm{C}-\mathrm{N}$ bond always involves the styryl-bonded nitrogen atom. The $\mathrm{C}=\mathrm{C}$ double bond, particularly of molecule $\mathrm{A}$, is unrealistically short, and the $=\mathrm{C}-\mathrm{C}$ bond is too long. This points to cocrystallization of two (or more) conformers that differ by rotation around the $\mathrm{Ru}-\mathrm{C}$ vinyl bond. ${ }^{51}$ All our attempts to resolve this apparent disorder were, however, unsuccessful. The plane of the styryl ligand is roughly coplanar to the urea function with a tilt angle of $5.3^{\circ}$ for molecule $\mathrm{A}$ and $8.2^{\circ}$ for molecule B. This contrasts to a $29.1^{\circ}$ (molecule A) or $28.6^{\circ}$ (molecule B) tilt angle between the terminal phenyl ring and the urea plane. Common to both molecules is a considerably larger quinoidal distortion $^{52}$ of the coplanar styryl unit than of the other phenyl ring. Thus, the opposing $\mathrm{CH}-\mathrm{CH}$ bond lengths of the phenylene substituent are about $8 \mathrm{pm}$ longer than the flanking ones, whereas this difference is reduced to about $3 \mathrm{pm}$ for the monosubstituted phenyl ring at the other terminus. This provides more evidence for efficient conjugation between the styryl ruthenium and the urea functions in these complexes.

Voltammetry on complex $\mathbf{5}$ showed two consecutive oneelectron oxidations with a half-wave potential separation similar

(51) Hall, M. B.; Niu, S.; Reibenspies, J. H. Polyhedron 1999, 18, 17171724.

(52) Rathore, R.; Lindeman, S. V.; Kumar, A. S.; Kochi, J. K. J. Am. Chem. Soc. 1998, 120, 6931-6939. to but half-wave potentials $\sim 105 \mathrm{mV}$ lower than those of complexes 2a,b (Figure 11). This sizable cathodic shift upon replacement of the electron-withdrawing 4,6-dioxo-1,4,5,6tetrahydropyrimidin-2-yl entity by a phenyl group is an indication of at least some electronic conjugation across the entire styryl urea moiety. IR-spectra recorded during the first oxidation revealed a blue-shift of the $\mathrm{Ru}-\mathrm{CO}$ band of $54 \mathrm{~cm}^{-1}$ upon the first oxidation which is identical to those observed for the $\mathbf{2 a} \mathbf{a}, \mathbf{b}$ and 3a,b dimers within the error margins (Figure 12). Due to the absence of the 4,6-dioxo-1,4,5,6-tetrahydropyridinyl substituent, the spectral pattern in the $1750-1500 \mathrm{~cm}^{-1}$ range is much simpler and again reveals hardly any shift of the urea carbonyl and $\mathrm{CNH}$ bands upon oxidation. There is likewise only a small red-shift of the $\mathrm{NH}$ bands from 3423 and $3400 \mathrm{~cm}^{-1}$ to 3415 and $3384 \mathrm{~cm}^{-1}$ (see Figure S13 of Supporting Information). Just like the $N$-4,6-dioxo-1,4,5,6-tetrahydropyrimidin-2yl- $N^{\prime}$ (4-ethenylphenyl) (styryl Upy) ruthenium complexes $\mathbf{2 a , b}$, $\mathbf{5}$ displays intense $\pi \rightarrow \pi^{*}$ and LMCT charge-transfer absorptions at 312 and $337 \mathrm{~nm}$ and, at $510 \mathrm{~nm}$, the weak absorption of a square pyramidal $\mathrm{Ru}$ (II) $\mathrm{ML}_{5}$ system. During stepwise oxidation, rather intense absorption bands at $\sim 450 \mathrm{~nm}$ and at $766 \mathrm{~nm}$ appear (Figure 13). The red-shift of the low-energy band of $\mathbf{5}^{\mathbf{}}$ when compared to $\left(\mathbf{2} \mathbf{a}^{\circ}\right)_{2}{ }^{\mathbf{2}}$ relates to the lower electronaccepting/stronger electron-donating properties of the urea substituent compared to those of the Upy one which destabilizes the corresponding donor orbital(s) below the SOMO.

Quantum Chemistry. Quantum chemical studies were performed in order to better understand the behavior of the dimeric Upy complexes and, in particular, to rationalize the absence of any detectable electronic coupling between individual monomers across the strong quadruple hydrogen bond. The calculations were performed on simplified models of monomers $\mathbf{U p y}^{\mathbf{M e}}, \mathbf{2}^{\mathbf{M e}}$, $\mathbf{3}^{\mathrm{Me}}$, and $\mathbf{5}^{\mathrm{Me}}$ and dimers $\left(\mathbf{U} \mathbf{p y} \mathbf{y}^{\mathbf{M e}}\right)_{2}$ (see Figure S14, Supporting Information) and $\left(2^{\mathrm{Me}}\right)_{2}$ with $\mathrm{PMe}_{3}$ instead of $\mathrm{P}^{i} \mathrm{Pr}_{3}$ ligands and methyl substituents instead of ${ }^{n}$ butyl or 2-propenyl groups on the quaternary carbon of the 4,6-dioxo-1,4,5,6-tetrahydropyrimidinyl ring (Chart 3). Calculated minimum structures agree reasonably well with the experimentally observed ones (X-ray) as is evident from the comparison in Table 4 (see also Chart 4). With the exception of bond C11-N2 which connects the urea function to the pyrimidinedione ring, all other bond lengths differ by, at most, $4 \mathrm{pm}$. The quinoidal distortion of the styryl ring, however, is not accounted for by the calculations.

IR-spectroscopy of dimers $(\mathbf{2 a})_{2},(\mathbf{2 b})_{2}$, and $(\mathbf{3 b})_{2}$ has given multiple intense absorptions in the carbonyl, $\mathrm{C}=\mathrm{C}$ and $\mathrm{CNH}$ regions. DFT calculations on $\mathbf{2}^{\mathrm{Me}}, \mathbf{3}^{\mathrm{Me}}$ and $\mathbf{5}^{\mathrm{Me}}$ and their oxidation products describe the energy of the $\mathrm{Ru}-\mathrm{CO}$ stretching vibration $v(\mathrm{CO})$ and its shift to higher wavenumbers upon oxidation reasonably well (Table 5). Similar to our results on other vinyl ruthenium complexes ${ }^{25,27}$ the shift of $v(\mathrm{CO})$ upon the first oxidation is underestimated which 


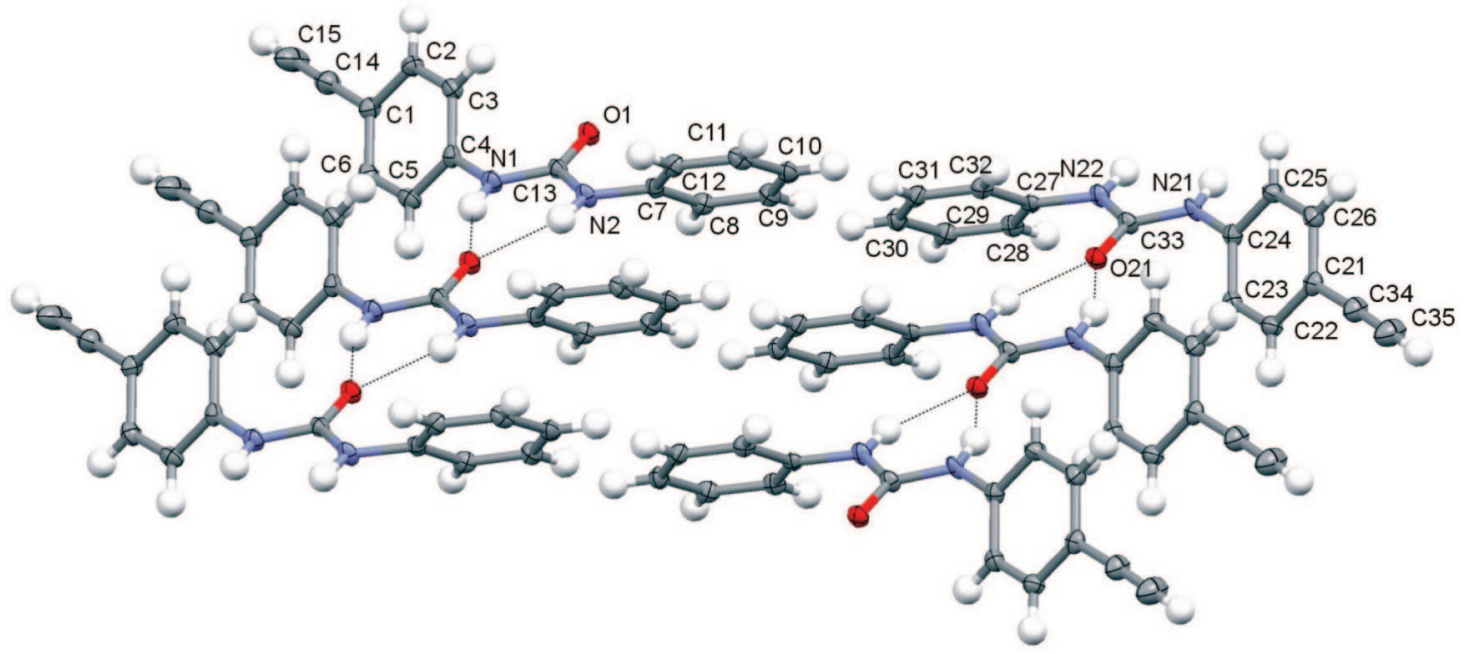

Figure 9. ORTEP plot of the chains of hydrogen-bonded molecules of alkyne $\mathbf{4}$ with ellipsoids set at a 50\% probability level. Intermolecular hydrogen bonds are indicated as dotted lines.

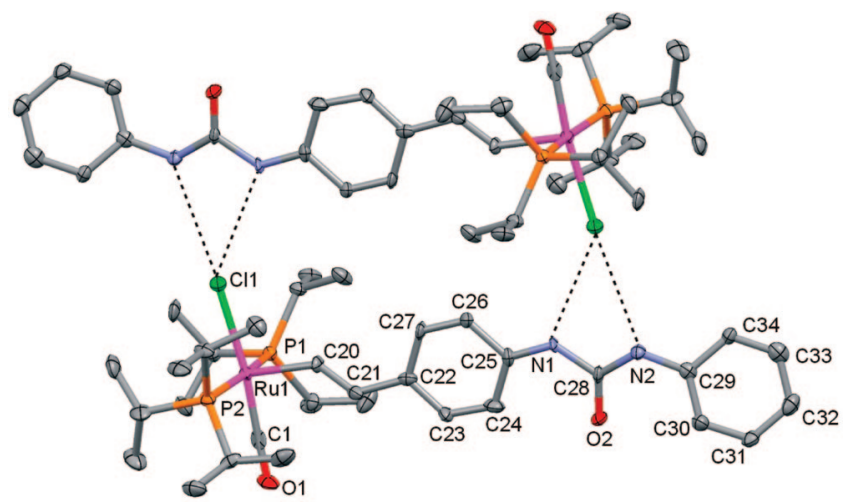

Figure 10. ORTEP plot of a weakly associated dimer of two molecules A of complex $\mathbf{5}$ with ellipsoids set at a $50 \%$ probability level. Hydrogen atoms are omitted for clarity; intermolecular hydrogen bonds are indicated as dotted lines.
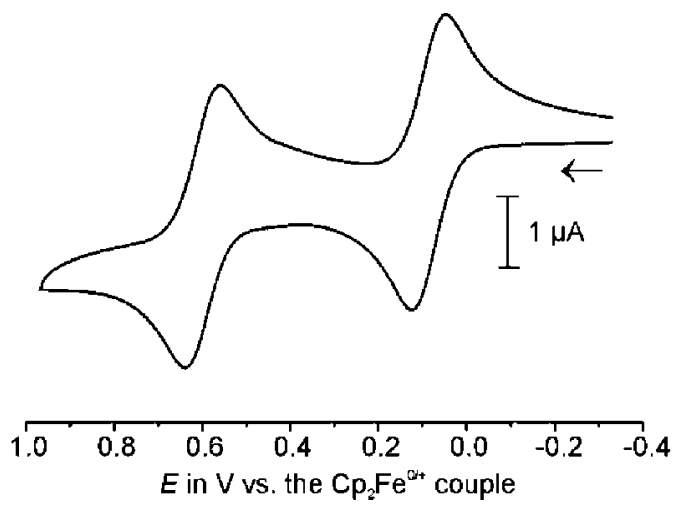

Figure 11. Voltammogram of a $0.23 \mathrm{mM}$ solution of complex 5 in $\mathrm{CH}_{2} \mathrm{Cl}_{2}$ $/ \mathrm{NBu}_{4} \mathrm{PF}_{6}(0.1 \mathrm{M})$ at $\mathrm{rt}$ and $v=0.1 \mathrm{~V} / \mathrm{s}$.

points to an overestimated contribution of the modified styryl ligand to the redox orbital. We felt that a more detailed analysis of these bands and their evolution upon oxidation might provide a tool to experimentally map the extent to which the developing positive charges are delocalized into the crucial hydrogen-bonding segment of these molecules. In order to aid the assignment of the multiple absorptions in that region we calculated the stretching frequencies of the $N$-4,6-dioxo-5,5-dimethyl-1,4,5,6-tetrahydropyrimidin-2-yl-

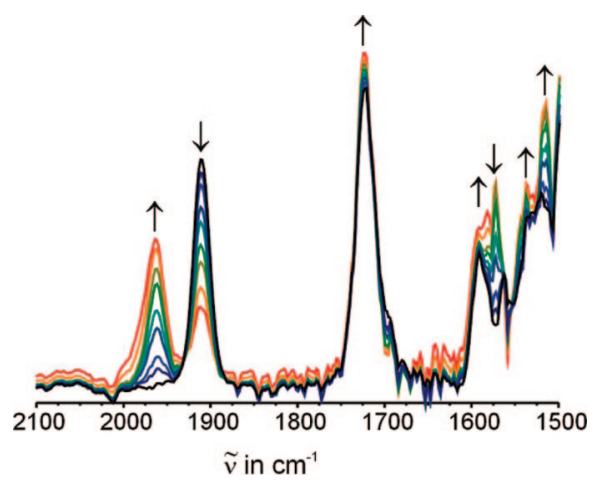

Figure 12. IR spectroelectrochemistry on complex $5\left(\mathrm{DCE} / \mathrm{NBu}_{4} \mathrm{PF}_{6}, \mathrm{rt}\right)$ in the carbonyl, $C=\mathrm{N}$ and $\mathrm{C}=\mathrm{C}$ regions.

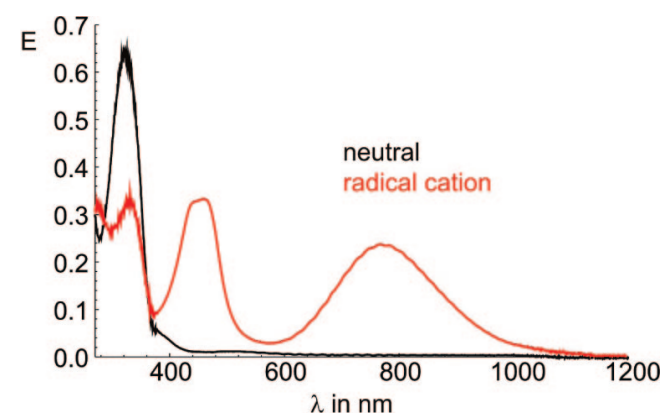

Figure 13. UV/vis/NIR spectra of complex 5 (black trace) and of $[5]^{\circ+}$ (red trace) in (DCE/NBu $\left.\mathrm{NF}_{6}, \mathrm{rt}\right)$.

$N^{\prime}$-methylurea dimer $\left(\mathbf{U p y}^{\mathrm{Me}}\right)_{2}$ (Chart 3). Calculated vibrational spectra are in excellent agreement with the experimental ones as is shown in Table 2. A comparison of the vibrational frequencies calculated for the $\left(\mathbf{U p y}^{\mathrm{Me}}\right)_{2}$ dimer with those of the $\mathbf{U p y}{ }^{\mathrm{Me}}$ monomer indicates that hydrogen bonding induces a sizable red-shift of the vibration formed by the combined asymmetric stretch $v(\mathrm{CO})_{\text {pmd, as }}$ and the $\delta(\mathrm{CNH})_{\text {urea }}$ bending mode of about $50 \mathrm{~cm}^{-1}$. This calculated shift does not substantially depend on density functional and quality of the basis set (Table S6 of the Supporting Information). Vibrational analyses on $\left(\mathbf{U p y}^{\mathrm{Me}}\right)_{2}$ also help in the assignment of the individual IR bands of the Upy-substituted styryl complexes. Plots indicating the atomic motions for every crucial vibration in that spectral region are shown as Figure 
Chart 3. Model Compounds Used in the Calculations

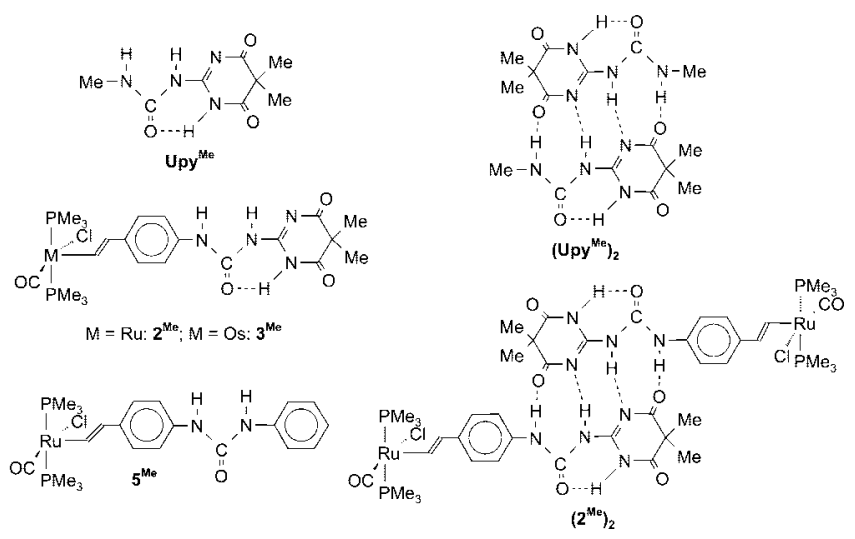

Table 4. G03/B3LYP Calculated Symmetry Averaged Bond Lengths $(\AA)$ for Model Complexes $\mathbf{2}^{\mathrm{Me}}$ and $\mathbf{5}^{\mathrm{Me}}$ and the Comparison with Experimental Ones

\begin{tabular}{lcllll}
\hline & \multicolumn{2}{c}{$2^{\text {Me }}$} & & \multicolumn{2}{c}{$5^{\text {Me }}$} \\
\cline { 2 - 3 } & calculated & experimental & & calculated & \multicolumn{1}{c}{ experimental $^{\mid a}$} \\
\hline $\mathrm{Ru}-\mathrm{C}_{1}(\mathrm{CO})$ & 1.828 & $1.820(12)$ & & 1.828 & $1.816(9)$ \\
$\mathrm{Ru}-\mathrm{Cl}$ & 2.452 & $2.432(2)$ & & 2.454 & $2.4622(16)$ \\
$\mathrm{Ru}-\mathrm{P}$ & 2.389 & $2.394(2)$ & & 2.389 & $2.389(2), 2.406(2)$ \\
$\mathrm{Ru}-\mathrm{C}_{2}$ & 2.001 & $1.985(8)$ & & 2.013 & $2.0007(8)$ \\
$\mathrm{C}_{2}-\mathrm{C}_{3}$ & 1.349 & $1.325(12)$ & & 1.348 & $1.302(11)$ \\
$\mathrm{C}_{3}-\mathrm{C}_{4}$ & 1.473 & $1.487(11)$ & & 1.474 & $1.429(15)$ \\
$\mathrm{C}_{4}-\mathrm{C}_{5}$ & 1.408 & $1.372(12)$ & & 1.408 & $1.431(14), 1.422(12)$ \\
$\mathrm{C}_{5}-\mathrm{C}_{6}$ & 1.391 & $1.401(11)$ & & 1.389 & $1.337(16), 1.353(16)$ \\
$\mathrm{C}_{6}-\mathrm{C}_{7}$ & 1.403 & $1.369(11)$ & & 1.403 & $1.414(12), 1.409(15)$ \\
$\mathrm{C}_{7}-\mathrm{N}_{1}$ & 1.417 & $1.425(10)$ & & 1.412 & $1.433(13)$ \\
$\mathrm{N}_{1}-\mathrm{C}_{8}$ & 1.372 & $1.337(10)$ & & 1.387 & $1.370(15)$ \\
$\mathrm{C}_{8}-\mathrm{N}_{2}$ & 1.441 & $1.434(10)$ & & 1.390 & $1.329(15)$ \\
$\mathrm{N}_{2}-\mathrm{C}_{9}$ & 1.381 & $1.301(10)$ & & 1.410 & $1.421(12)$ \\
\hline
\end{tabular}

${ }^{a}$ Data for molecule B.

Chart 4. Numbering Scheme of Table 4

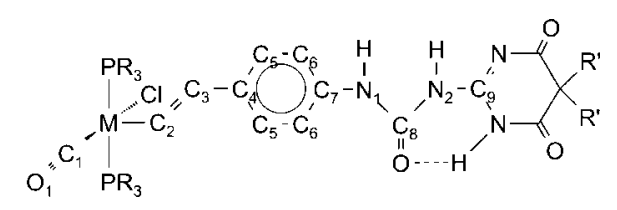

S15 of the Supporting Information. With these assignments at hand it becomes clear that oxidation of the vinyl complexes only affects the energy of the $\mathrm{NH}$ bend of the urea nitrogen that is directly attached to the styryl ligand. There is only a negligible shift of all other local vibrators of the urea and pyrimidinedione functionalities that are directly involved in hydrogen bonding. This provides another piece of evidence that these moieties do not contribute to the redox orbitals.

Single-point DFT calculations on the experimental geometry of the dimeric $\mathrm{Ru}$ complex $\left(\mathbf{2}^{\mathrm{Me}}\right)_{2}$ underscore these findings. The highest-lying orbitals HOMO and HOMO-1 are each localized on only one $\mathrm{Ru}-$ styryl part and receive only minor contributions from the Upy substituent (see Figure 14). The calculated HOMO of an isolated monomer $2^{\mathrm{Me}}$ is almost identical to that of the corresponding one of the dimeric model species $\left(2^{\mathrm{Me}}\right)_{2}$ and of the phenylurea model complex $\mathbf{5}^{\mathrm{Me}}$ (Figure 15). The HOMO - HOMO-1 separation of $0.051 \mathrm{eV}$ indicates that electronic coupling ${ }^{53}$ between the two monomers is low. Calculated spin densities of $\left(\mathbf{2}^{\mathrm{Me}}\right)_{2}{ }^{++}$(see Table 6, Figure 16)

(53) Newton, M. D. Chem. Rev. 1991, 91, 767-792.
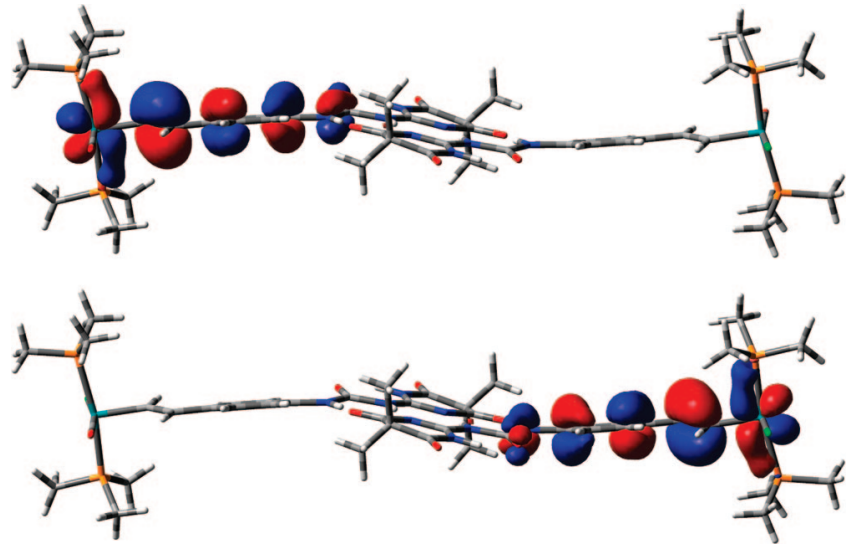

Figure 14. Plots of the HOMO (top) and HOMO-1 (bottom) of the dimeric model complex $\left(2 \mathbf{a}^{\mathrm{Me}}\right)_{2}$.
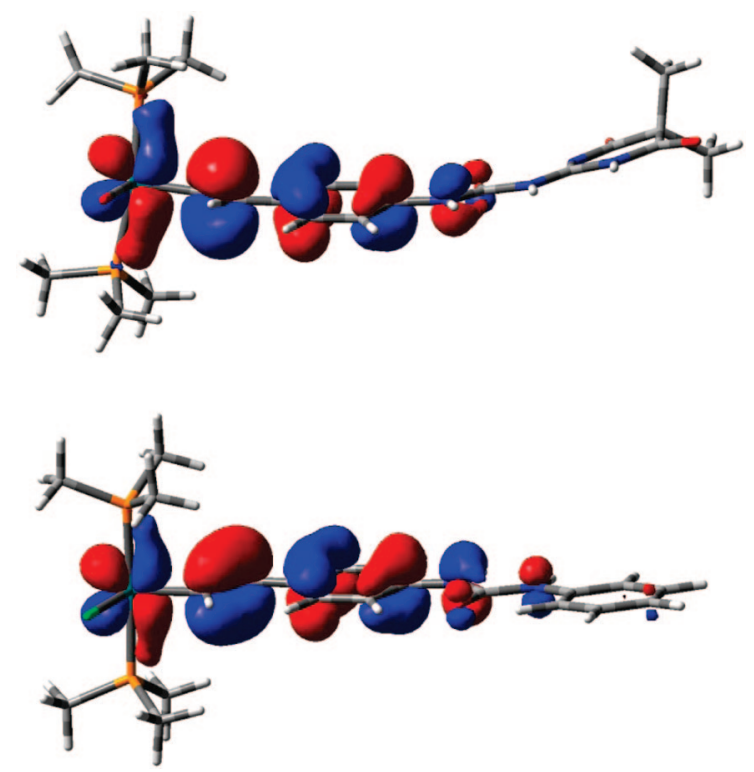

Figure 15. Plots of the HOMOs of monomeric model complexes $2^{\mathrm{Me}}$ (top) and $\mathbf{5}^{\mathrm{Me}}$ (bottom).

Table 6. DFT G03/PBE0 Calculated Spin Densities for the Dimeric Model Complex $\left(2^{\mathrm{Me}}\right) 2^{\cdot+}$ Expressed in Terms of Composing Fragments

\begin{tabular}{cccccccc}
\hline & Ru1 & Ru2 & Et1 & Ph1 & Cl1 & C01 & urea1 \\
\hline spin density & 0.437 & 0.016 & 0.328 & 0.183 & -0.003 & -0.022 & 0.039 \\
\hline
\end{tabular}

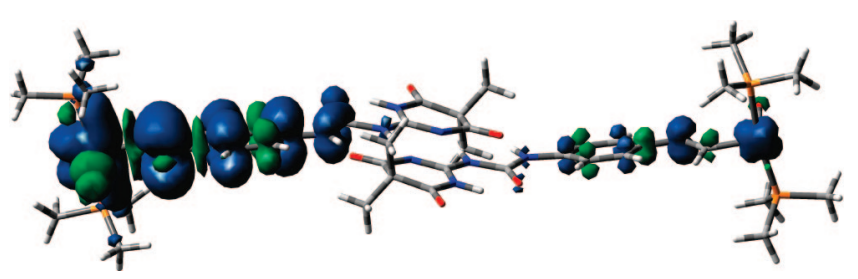

Figure 16. Calculated spin densities for the monooxidized form $\left(2^{\mathrm{Me}}\right)_{2}{ }^{\cdot+}$ of the dimeric model complex.

also show that there is very little spin delocalization between individual monomers. The total contribution of the second styryl ruthenium entity is thus only 0.016 . Taken together, the quantum chemical results fully agree with those of our experiments in the major point of this study: There is hardly any charge and spin delocalization across the quadruply hydrogen-bonding Upy 
motif, at least in the present case of styryl ruthenium and osmium complexes. This leads to valence localization on one of the terminal redox-active styryl ruthenium or osmium subunits in the one-electron oxidized mixed-valent state.

\section{Discussion}

Our results indicate efficient electron delocalization within the metal styryl entities of complexes $\mathbf{2} \mathbf{a}, \mathbf{b}, \mathbf{3 a}, \mathbf{b}$, and $\mathbf{5}$. From a structural viewpoint we infallibly observe rough coplanarity of the styryl group with the $\mathrm{Ru}(\mathrm{CO}) \mathrm{Cl}$ plane and only a slight rotation of the phenyl ring with respect to the $\mathrm{MCH}=\mathrm{CH}$ plane. Moreover, the quinoidal distortion of the styryl ring clearly surpasses that of the terminal one in complex $\mathbf{5}$. More relevant to the behavior in solution are the first redox potentials of complexes $\mathbf{2 a}, \mathbf{b}(0.19$ and $0.195 \mathrm{~V}), \mathbf{3 a}, \mathbf{b}(0.020$ and $0.015 \mathrm{~V})$, $5(0.085 \mathrm{~V})$, and of the simple styryl complex $\mathrm{Cl}(\mathrm{CO})\left(\mathrm{P}^{i} \mathrm{Pr}_{3}\right)_{2} \mathrm{RuCH}=\mathrm{CHPh}(0.27 \mathrm{~V})$. The data clearly indicate that the metal and the 4-substituent on the phenyl ring exert a strong influence on the redox potential. In contrast, electronic interactions between individual hydrogen bonded styryl metal complexes in dimers $(\mathbf{2 a})_{2},(\mathbf{2 b})_{2},(\mathbf{3 a})_{2}$ and $(\mathbf{3 b})_{2}$ are undetectably small. They neither lead to a splitting of half-wave potentials in electrochemistry nor to an intervalence chargetransfer absorption in electronic spectra as would be expected of even a weakly coupled mixed-valent system of class II. The only indication of such an interaction is the small calculated splitting of the HOMO and HOMO-1 orbitals of the model comples $\left(2^{\mathrm{Me}}\right)_{2}$ of $0.051 \mathrm{eV}$. In addition, none of these systems showed any $\mathrm{CO}$ bands besides that of the neutral and that of the dioxidized dicationic forms in IR spectroelectrochemistry even during the electrolysis. Comproportionation equilibria dictate that the corresponding radical cations must be present to some extent in solution besides the neutral and fully oxidized forms. The fact that we cannot detect them simply means that they have no inherent spectroscopic fingerprint different from the neutrals and the dications, i.e. the oxidized or reduced subunits of a mixed-valent dimer have the same $\tilde{v}(\mathrm{CO})$ as the fully oxidized dications or reduced neutrals, respectively. The seemingly one-step conversions of the neutrals to the dications clearly argue against an even moderate electronic coupling. In the presence of such coupling, two bands at similar but slightly different energies as in the isovalent states should be observed for the intermediate radical cation. ${ }^{54,55}$ Even IR changes of the $\mathrm{NH} \cdot \cdots \mathrm{N}=\mathrm{C}$ and $\mathrm{NH} \cdots \mathrm{O}=\mathrm{C}$ band pattern upon oxidation are restricted to those urea $\mathrm{NH}$ groups that are directly bonded to the styryl moiety.

The monomeric phenylurea derivative $\mathbf{5}$ produces the same two-wave pattern in electrochemistry with nearly identical splittings of half-wave potentials, the same oxidation-induced $\mathrm{CO}$ band shift and similar electronic bands in the oxidized state as the dimeric counterparts. The only difference is that each wave involves just one as opposed to two electrons per wave. Quantum chemistry indicates that conjugation in the present systems extends to the styryl moiety but not beyond. In particular, the $\mathrm{NH} \cdots N=\mathrm{C}$ and $\mathrm{NH} \cdots \mathrm{O}=\mathrm{C}$ moieties that are involved in the hydrogen bonding do not contribute to any of the occupied frontier orbitals. This shuts down on the electronic interactions between the bridged subunits in spite of the high charge and spin densities at the urea-bonded styryl ring as they

(54) Atwood, C. G.; Geiger, W. E. J. Am. Chem. Soc. 2000, 122, $5477-$ 5485 .

(55) Stoll, M. E.; Lovelace, S. R.; Geiger, W. E.; Schimanke, H.; HylaKryspin, I.; Gleiter, R. J. Am. Chem. Soc. 1999, 121, 9343-9351. are typical of ruthenium and osmium styryl complexes. This lets us conclude that in the absence of an electronic driving force for directional electron transfer between a (photo)donor and a (photo)acceptor the quadruply hydrogen-bridging Upy motif is unable to support efficient electronic coupling between the (redox active) styryl ruthenium or osmium end groups. The reasons for the deviating behavior of the analogous ferrocene system remain unclear at this point.

One may, of course, object that our failure to observe any electronic interactions across the Upy bridges of $(\mathbf{2 a})_{2},(\mathbf{2} \mathbf{b})_{2}$, $(\mathbf{3 a})_{2}$, and $(\mathbf{3 b})_{2}$ is simply due to disintegration of the dimers into monomers following oxidation. Our reasoning against such a scenario is as follows: If the oxidation would bring about dissociation into monomers, one might expect indicative changes of the $v(\mathrm{CO})_{\text {pmd, as }}+\delta(\mathrm{CNH})_{\text {urea }}$ vibration mode which, according to our quantum chemical calculations, is highly sensitive to whether the system is monomeric or dimeric in solution. This is, however, not the case. In addition, recent studies on hydrogen bonding between a urea donor and the 1,4dimethylpiperazine-2,3-dione hydrogen-bond acceptor revealed a $>2000$-fold binding strength increase upon urea oxidation. ${ }^{56}$ Similar arguments should also hold in our case.

\section{Conclusions}

Ruthenium and osmium styryl complexes with appended 4,6dioxo-1,4,5,6-tetrahydropyrimidinylurea (ureapyrimidinedione, Upy) substituents dimerize in an antiparallel arrangement by the quadruple hydrogen bridges of a DDAA ( $\mathrm{D}=$ hydrogen bond donor, $\mathrm{A}=$ hydrogen bond acceptor) motif. The dimeric structures observed in X-ray crystallography are maintained in nonpolar solvents as is shown by the characteristic low-field shifts of the NH protons in NMR spectroscopy. Combined data from conventional electrochemistry, from IR and UV/vis spectroelectrochemistry and from accompanying quantum chemical calculations indicate efficient electron delocalization within the metal styryl subunit of each dimer of complexes $(\mathbf{2 a})_{2},(\mathbf{2} \mathbf{b})_{2}$, $(\mathbf{3 a})_{2}$, and $(\mathbf{3 b})_{2}$ and that of the phenylurea complex $\mathbf{5}$, but not beyond. In particular they show that in our case the quadruply hydrogen-bonding motif does not support any detectable electronic coupling between the reduced and oxidized metal styryl subunits. It appears, that the underlying reason is the negligible contribution of the $\mathrm{NH} \cdots \mathrm{N}=\mathrm{C}$ and $\mathrm{NH} \cdots \mathrm{O}=\mathrm{C}$ groups on the urea and pyrimidinedione moieties that are involved in the hydrogen bonding to the occupied frontier orbitals. These findings contrast the highly efficient electron transfer across hydrogen bridges supported by closely related multiply hydrogen-bonded motifs. It also differs from the analogous ferrocene system, whose mixed-valent radical cation seemingly constitutes a borderline class II/III system. ${ }^{23}$ The reasons for this dichotomy are presently under investigation by our group.

Acknowledgment. This work is dedicated to Prof. Dr. Otto J. Scherer at the occasion of his 75th birthday. It was generously supported by Deutsche Forschungsgemeinschaft (Grants Wi 1262/ 7-1 and 436 TSE113/45/0-1) and by the Grant Agency of the Academy of Sciences of the Czech Republic (KAN100400702) and the Ministry of Education of the Czech Republic (Grant COST OC 139). We also thank Dr. Biprajit Sarkar for the recording of the EPR spectrum of partially oxidized $2 \mathbf{a}^{*}$.

(56) Woods, J. E.; Ge, Y.; Smith, D. K. J. Am. Chem. Soc. 2008, 130, 10070-10071. 
Supporting Information Available: Synthetic procedures and characterization of new compounds and details of the crystal structure determinations and the quantum chemical calculations, figures displaying the crystallographically determined structures of of alkyne 1b (Figure S1), packing diagrams of alkynes $\mathbf{1 b}$ (Figure S2) and 4 (Figure S11), packing diagrams of complexes 2a (Figure S3) and 5 (Figure S12), hydrogen-bonding motif with the $\mathrm{CH}_{2} \mathrm{Cl}_{2}$ solvent of crystallization of complex $\mathbf{2 a}$ (Figure S4); tables with details of the crystal data and structure refinement (Tables S1-S5); tables detailing the calculated vibrations of the model $\mathbf{U p y}^{\mathbf{M e}}$ monomer and the $\left(\mathbf{U p y}^{\mathbf{M e}}\right)_{2}$ dimer (Table S6), TD DFT (G03/B3LYP/CPCM- $\mathrm{CH}_{2} \mathrm{Cl}_{2}$ ) calculated lowest lying excitation energies (eV) for $2^{\mathrm{Me}}$ (Table S7), $2^{\mathrm{Me} \cdot+}$ (Table S8), $\mathbf{5}^{\mathrm{Me}}$ (Table S9) and $\mathbf{5}^{\mathrm{Me} \cdot+}$ (Table S10), Figures displaying the
${ }^{1} \mathrm{H}$ NMR spectrum of a $\mathrm{CD}_{2} \mathrm{Cl}_{2}$ solution of complex $\mathbf{2 a}(1.1$ $\mathrm{mM}$ ) in $0.1 \mathrm{M} \mathrm{NBu}_{4} \mathrm{PF}_{6}$ (Figure S5), the voltammogram of complex 2a in $\mathrm{CH}_{2} \mathrm{Cl}_{2} / \mathrm{MeOH}$ (Figure S6), the ${ }^{1} \mathrm{H} \mathrm{NMR}$ spectrum of a mixture of complexes $\mathbf{2} \mathbf{a}$ and $\mathbf{3 b}$ in $\mathrm{CD}_{2} \mathrm{Cl}_{2}$ at various temperatures (Figure S7), IR spectroscopic changes upon the first (Figure S8) and second (Figure S10) oxidation of complex $\mathbf{2} \mathbf{b}$ and in the $\mathrm{NH}$ region of complex $\mathbf{2 a}$ (Figure S9) and complex 5 (Figure S13), the calculated ground-state structure of the $\left(\mathbf{U p y}^{\mathbf{M e}}\right)_{2}$ dimer (Figure S14) and calculated atom displacements during the vibrations of model complex $\left(\mathbf{U p y}^{\mathbf{M e}}\right)_{2}$ in the $1750-1500 \mathrm{~cm}^{-1}$ region (Figure S15). This material is available free of charge via the Internet at http://pubs.acs.org.

JA809566G 